\title{
The role of smectites in the electrical conductivity of active hydrothermal systems: electrical properties of core samples from Krafla volcano, Iceland
}

\author{
L. Lévy, ${ }^{1,2,3}$ B. Gibert, ${ }^{4}$ F. Sigmundsson, ${ }^{2}$ Ó.G. Flóvenz, ${ }^{3}$ G.P. Hersir, ${ }^{3}$ P. Briole ${ }^{1}$ and \\ P.A. Pezard ${ }^{4}$ \\ ${ }^{1}$ Laboratoire de Géologie, Ecole Normale Supérieure - PSL Research University, CNRS, UMR 8538, Paris, France. E-mail: lea.levy@ens.fr \\ ${ }^{2}$ Nordic Volcanological Center, Institute of Earth Sciences, University of Iceland, 101 Reykjavik, Iceland \\ ${ }^{3}$ ÍSOR-Iceland GeoSurvey, Grensásvegur 9, 108 Reykjavik, Iceland \\ ${ }^{4}$ Géosciences Montpellier, Université de Montpellier, Montpellier, France
}

Accepted 2018 August 16. Received 2018 July 20; in original form 2017 November 21

\begin{abstract}
S UM M A R Y
The underground circulation of hot water, of interest for geothermal energy production, is often indirectly inferred from the presence of minerals formed by hydrothermal alteration at different temperatures. Clay minerals, such as smectite and chlorite, can be mapped from the surface using electrical soundings and give information about the structure of the geothermal system. Here, we investigate the specific role of smectite in the electrical response of igneous basaltic rocks and evaluate what physical processes make smectite a better electrical conductor than surrounding minerals. Laboratory measurements of cation exchange capacity (CEC), mineralogy, porosity and electrical conductivity are presented for 88 core samples from four boreholes at the Krafla volcano, Northeast Iceland. CEC is found to be a reliable measure of the smectite weight fraction in these volcanic samples, through a comparison with an independent quantification of the smectite content using Rietveld refinements of X-ray diffraction patterns. The bulk electrical conductivity, measured at fluid conductivities in the range $0.02-11.7 \mathrm{~S} \mathrm{~m}^{-1}$, increases non-linearly with the fluid conductivity for samples with high smectite content. This non-linear variation is fitted with a function and a model for a conduction process through connected interlayer spaces within smectite. The process differs from electrical double layer conduction, which involves only cations on the crystal edges of smectite, not in the interlayer spaces. The laboratory results can help refine interpretations of electrical soundings in the context of geothermal exploration.
\end{abstract}

Key words: Electrical properties; Hydrothermal systems.

\section{INTRODUCTION}

Electrical resistivity soundings are used in exploration geophysics because resistivity of rocks is sensitive to the presence of natural elements relevant for industrial and research purpose: clay minerals, sulphides and metal oxides, molten magma and water of varying quantity, salinity and temperature. Discriminating the influence of these different components is challenging because of the heterogeneity of the conductive media and the wide range of conductivities of each of its component. We address here the particular contribution of expandable minerals (subcategory of clay minerals, e.g. smectite) to the electrical signature of the investigated area. Expandable minerals are abundant in volcanic geothermal systems (Meunier 2005), in subduction zones (Hyndman et al. 1997) and in some major faults (Chester et al. 2013). In volcanic systems, expandable minerals precipitate readily in permeable horizons during the circulation of hydrothermal fluids (Beaufort et al. 1995; Patrier et al. 1996). They are therefore amongst the first alteration minerals to precipitate from hydrothermal activity. At low temperature $\left(80^{\circ} \mathrm{C}-180^{\circ} \mathrm{C}\right)$, these expandable minerals are thermodynamically stable and form a clay cap observed in geothermal systems, that can be mapped by electrical soundings (e.g. Árnason et al. 2000; Flóvenz et al. 2012). Above $180{ }^{\circ} \mathrm{C}$, the expandable minerals are progressively replaced by chlorite and other 'high-temperature' minerals (Kristmannsdóttir 1975), if a thermodynamic equilibrium can be reached. The alteration mapping of an equilibrated geothermal system (Walker 1960; Kristmannsdóttir 1979; Alt et al. 1986) can be carried out by electrical soundings (Flóvenz et al. 1985; Hersir \& Björnsson 1991; Árnason et al. 2010), based on the lower electrical conductivity of chlorite (nonexpandable) compared to smectite (expandable) and the intermediate conductivity of mixed-layer clays (Flóvenz et al. 2005). One of the 
current challenges in geothermal exploration is to distinguish between active and inactive sections of a geothermal system. Mapping the presence of smectite outside the clay cap would be a step forward to meet that challenge as smectite can indicate recent circulations of hydrothermal fluids (Beaufort et al. 1995). However, this requires more understanding of the physical processes responsible for the unique conductive behaviour of smectite, related to its high cation exchange capacity (CEC), as shown by e.g. Flóvenz et al. (2005) and Revil et al. (2017a).

Electrical conductivity of rocks containing clay minerals has been extensively studied from a theoretical and experimental point of view. The pioneering study of Archie (1942) showed that electrical resistivity of sandstones depends on salinity of the pore fluid as well as on the quantity of pore fluid transporting electrical charges (usually lower than the total porosity). Electrical measurements on basaltic samples from Iceland were used by Flóvenz et al. (1985) to show that the temperature dependence of resistivity was different from what one would expect if only pore fluid was contributing, emphasizing the importance of clay contribution to the measured conductivity. The clay contribution was introduced by Hill \& Milburn (1956) with a constant shaliness parameter. Following this idea, Rink \& Schopper (1974) wrote the bulk conductivity as a linear function of the fluid conductivity with two constant parameters independent of the salinity: the 'formation factor' $F$ accounting for the topology of the pore space and the 'surface conductivity' $C_{\mathrm{s}}$ —also called 'interface conductivity' by Flóvenz et al. (1985). In these studies, $C_{\mathrm{s}}$ represents a contribution from the clays to conduction, which is much lower than the contribution of the pore fluid. Limits of the linear function had however been shown by Waxman \& Smits (1968), based on a large set of measurements on shaly sands and the use of linear-scale representation. Moreover, the possibility of electrical conduction along a pathway of connected clays in the rock matrix (not only along the interface clay-water) was mentioned by Vinegar \& Waxman (1984), based on the absence of charge accumulation beyond a certain clay content. However, such a model was not formulated, partly because sedimentary samples with high content of expandable clay minerals are not easily manipulated in the laboratory (Waxman \& Thomas 1974). Since altered igneous samples can have a high content of expandable clay minerals and yet be manipulated in the laboratory, the study of such samples can reveal the conduction processes for high smectite content. Our work is a step in that direction, following the work carried out by Flóvenz et al. (2005) and Kristinsdóttir et al. (2010) with Icelandic basaltic samples at different alteration stages.

Three types of properties have been measured in the laboratory on 88 Icelandic igneous basaltic core samples: chemistry (CEC), mineralogy (XRD) and petrophysical properties including porosity, grain density and electrical impedance measurements at six distinct pore water conductivities. We focus on the in-phase conductivity of these core samples, which is relevant when studying the role of smectite and other expandable minerals. The samples are from the well-studied Krafla high-temperature geothermal field, where cores are available in four boreholes, down to $700 \mathrm{~m}$ (Fig. 1). This field, where a geothermal powerplant is operated, is located within the caldera of the Krafla central volcano (Sigmundsson 2006) in northeast Iceland. The texture of our samples varies between fully glassy basalt (tuff, hyaloclastite) to highly crystalline basalt (intrusions). The smectite content varies up to 50 wt. per cent, which is more than twice as the maximum values found in previous studies [15 per cent in Waxman \& Smits (1968), 25 per cent in Flóvenz et al. (2005) and Revil et al. (2017a)].

\section{ELECTRICAL CONDUCTIVITY OF HYDROTHERMALLY ALTERED ROCKS}

\subsection{Cation exchanges in clay minerals}

Smectite and chlorite are two major alteration minerals in basalts, both belonging to the phyllosilicate (sheet silicates) family. Their cationexchange properties are, however, different. All minerals in the phyllosilicates family carry a permanent charge in the sheets, varying from 0 to 2 per $\mathrm{Si}_{4} \mathrm{O}_{10}$ (half unit cell). Drawings of several sheet silicates are shown in Fig. 2. This charge can be compensated in the intersheet 'interfoliar' space by hydrophilic cations $(\mathrm{Na}, \mathrm{Ca})$ or hydrophobic cations $(\mathrm{K})$ or by a brucitic layer $\left(\right.$ polymer of $\left.\mathrm{Mg}(\mathrm{OH})_{6}\right)$ in the case of chlorite (Ferrage et al. 2005). Below 0.7 charges per $\mathrm{Si}_{4} \mathrm{O}_{10}$ (smectite), weak Coulombic bondings allow the penetration of water with any cations, which in turn causes the structure to expand and allows cation exchanges. Around 0.7 charges per $\mathrm{Si}_{4} \mathrm{O}_{10}$ (vermiculite) and beyond (illite, micas), cation exchange properties depend on the cation: hydrophilic cations will be accompanied by water and allow cation exchanges, while hydrophobic cations will be more attracted by the crystal than by water, seal the structure and prevent cation exchanges, as illustrated in Fig. 2. Most minerals having more than 0.7 charges per $\mathrm{Si}_{4} \mathrm{O}_{10}$ are K-saturated (muscovite and illite) and therefore non-expandable. The brucitic layer in chlorite ( 1 charge per $\mathrm{Si}_{4} \mathrm{O}_{10}$ ) prevents any water intake or cation exchanges in the interlayer space.

Cation exchanges are key phenomena to understand the deviations from Archie's theory. The CEC of minerals is the sum of the so-called 'permanent CEC' (e.g. cation exchanges in the interlayer spaces for phyllosilicates; in the channels for zeolites) and the 'variable CEC' (cation exchanges on crystal edges). The variable CEC increases with the $\mathrm{pH}$ because a decrease of $\mathrm{H}^{+}$concentration in water causes a release of $\mathrm{H}^{+}$cations occupying external exchange sites. The permanent CEC is $\mathrm{pH}$-independent (Lyklema 2001).

The total CEC of smectite, which includes 70-97 per cent of permanent CEC and the rest of variable CEC (Vogt \& Köster 1978; Lagaly 1981), is much higher than the total CEC of non-expandable phyllosilicates (see Table 1), where only the variable CEC contributes by definition. A linear correlation between the CEC and the smectite fraction was found by Hower \& Mowatt (1966) in a series of smectite-illite samples, emphasizing that cation exchanges mostly take place in smectite. 


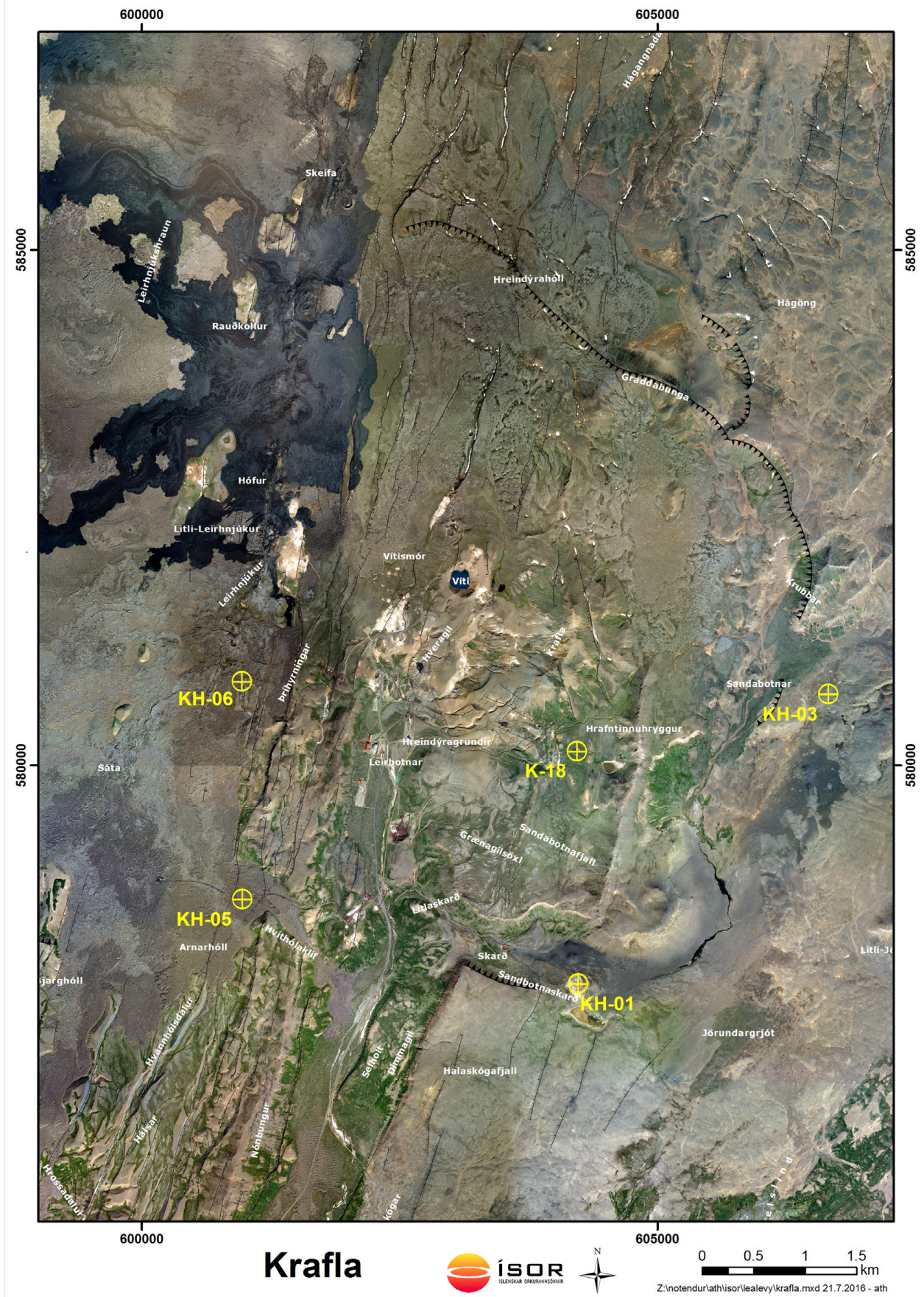

Figure 1. Aerial map of the Krafla high-temperature geothermal field. The caldera rim is marked with a black line. The four cored boreholes used in this study are marked in yellow: KH-01, KH-03, KH-05 and KH-06. A fifth borehole, K-18 is also shown for reference, as it has been used extensively for geophysical logging purposes. However, no core is available from it.

\subsection{Bulk conductivity of water-saturated rocks}

For a sinusoidal voltage $U(t)=U_{0} \cos \left(\omega t+\varphi_{1}\right)$ and current $I(t)=I_{0} \cos \left(\omega t+\varphi_{2}\right)$, the electrical impedance $Z$ is given by $U(t)=Z I(t)$. Due to the alternating character of the voltage and current, $Z$ is a complex number and can be written in two different ways: (1) amplitude $|Z|$ and phase $\theta$; (2) in-phase impedance $Z$ ' and quadrature impedance $Z$ ' (eq. 1).

$Z=Z^{\prime}+\mathrm{i} Z^{\prime \prime}=|Z| \cos \theta+\mathrm{i}|Z| \sin \theta=|Z| e^{\mathrm{i} \theta}$

The electrical conductivity is an intrinsic parameter independent of the geometry of the sample. The conductivity $\sigma$ is calculated from the impedance $Z$, using the distance between electrodes, $L$, and the cross-sectional area of the cylinder, $S$ (see the electrical cell in Fig. A1). 


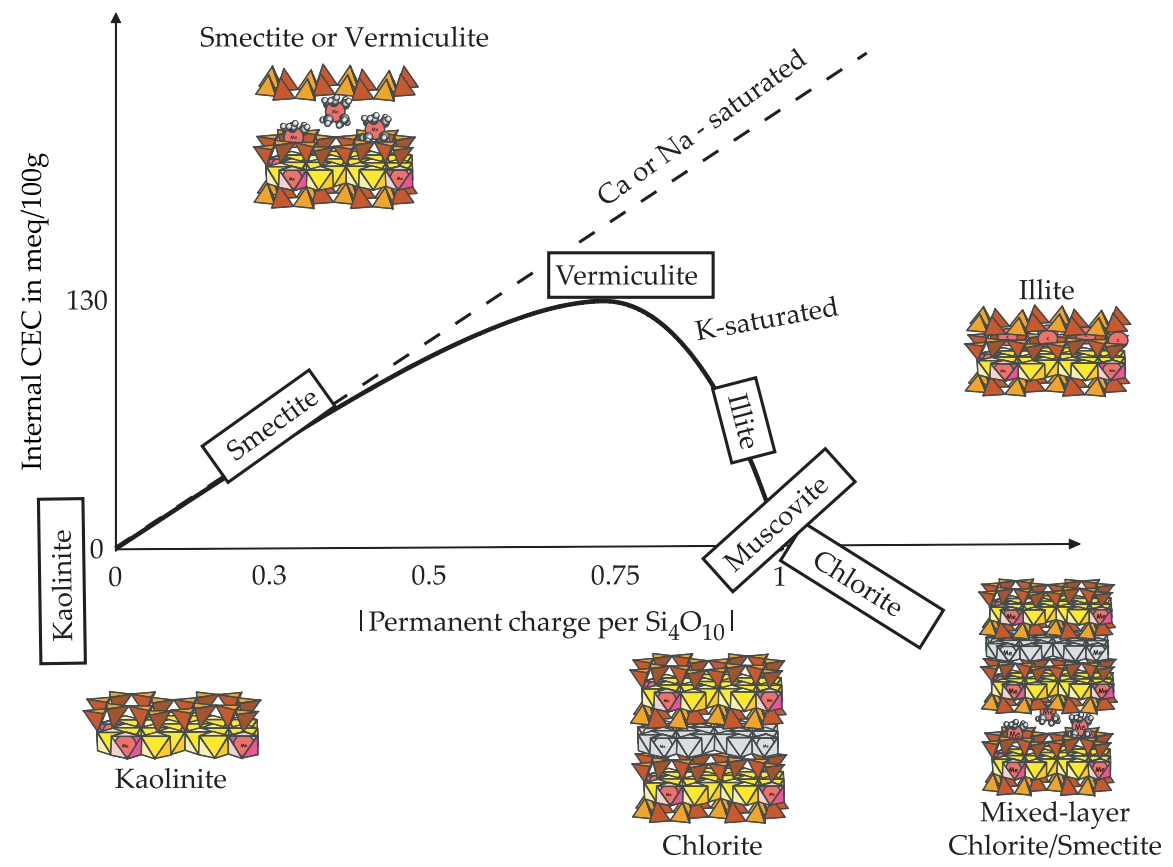

Figure 2. Schematic representation of the internal (permanent) cation exchange capacity (CEC) as a function of the structural permanent charge. Adapted from Bouchet et al. (2000) and Ferrage (2016).

Table 1. Examples of CEC values found in the literature $\left(1 \mathrm{meq} / 100 \mathrm{~g}=964.85 \mathrm{C} \mathrm{kg}^{-1}\right)$.

\begin{tabular}{lcc}
\hline & CEC meq/100g & References \\
\hline Smectite & $80-120$ & Bouchet et al. $(2000)$ \\
Vermiculite & $100-150$ & Bouchet et al. $(2000)$ \\
Chlorite & $5-15$ & Bouchet et al. $(2000)$ \\
Illite & $25-40$ & Bouchet et al. $(2000)$ \\
Kaolinite & $5-15$ & Bouchet et al. $(2000)$ \\
Heulandite & 300 & Fridriksson et al. $(2004)$ \\
Laumontite & $0.5-9$ & Dyer $(1991)$ \\
Wairakite & 0 & Ames $(1966)$ \\
\hline
\end{tabular}

It results in the in-phase conductivity $\sigma^{\prime}$ and the quadrature conductivity $\sigma^{\prime \prime}$ (eq. 2).

$\sigma=\frac{L}{S} \frac{1}{Z}=\frac{L}{S}\left(\frac{Z^{\prime}}{|Z|^{2}}-\mathrm{i} \frac{Z^{\prime \prime}}{|Z|^{2}}\right)=\sigma^{\prime}+\mathrm{i} \sigma^{\prime \prime}$

We review here existing models for relating the bulk in-phase conductivity to the fluid conductivity in porous media containing clays. Assuming that the electrical current transported by counter ions associated with clays travels along the same tortuous path as current associated to ions in pore water, Waxman \& Smits (1968) write the in-phase conductivity of a volume of rock $\left(\sigma_{\text {bulk }}\right)$ as the sum of two parallel conductivities: free ions in pore water $\left(\sigma_{\mathrm{w}}\right)$ and ions exchanged with minerals from the solid matrix $\left(\sigma_{\mathrm{s}}\right)$.

$\sigma_{\text {bulk }}=\frac{1}{F \phi}\left(\phi \sigma_{\mathrm{w}}+(1-\phi) \sigma_{\mathrm{s}}\right)=\frac{\sigma_{\mathrm{w}}}{F}+\frac{(1-\phi) \sigma_{\mathrm{s}}}{F \phi}$,

where $\phi$ is the volume fraction occupied by water (the porosity), $1-\phi$ the volume fraction occupied by the solid matrix and $F$ the formation factor. The product $F \phi$ is called the 'tortuosity'. An expression of $\sigma_{\mathrm{s}}$ is given in eq. (4), considering that all exchangeable ions in the solid contribute similarly to the solid conductivity:

$\sigma_{\mathrm{s}}=B \frac{m_{\mathrm{g}} \mathrm{CEC}}{V_{\mathrm{g}}}=B \rho_{\mathrm{g}} \mathrm{CEC}$,

where $B$ is the mobility of exchangeable ions, $V_{\mathrm{g}}, m_{\mathrm{g}}$ and $\rho_{\mathrm{g}}$ the volume, mass and density of the solid 'grain' and CEC the charge available per unit mass of solid. By relating the CEC to the ratio $Q_{\mathrm{v}}$ between charge available and volume of fluid available in the rock sample (eq. 5), the Waxman \& Smits formulation is obtained (eq. 6).

$Q_{\mathrm{v}}=\rho_{\mathrm{g}} \frac{(1-\phi)}{\phi} \mathrm{CEC}$ 
$\sigma_{\text {bulk }}=\frac{1}{F}\left(\sigma_{\mathrm{w}}+B Q_{\mathrm{v}}\right)$

This linear equation is extensively used to describe the in-phase electrical behaviour of saturated rocks (e.g. Pezard, Revil et al. 2017a). A deviation from this linear model was observed by Waxman \& Smits (1968) for fluid conductivities lower than $5 \mathrm{~S} \mathrm{~m}^{-1}$, especially for samples with high $Q_{\mathrm{v}}$. It was explained by an exponentially increasing mobility of exchange ions, associated with clays, with fluid conductivity:

$B\left(\sigma_{\mathrm{w}}\right)=\beta\left(1-\alpha e^{-\frac{\sigma_{\mathrm{w}}}{\gamma}}\right)$,

where $\beta$ is the maximum mobility of exchanged cations when $\sigma_{\mathrm{w}}>>\gamma, \alpha$ is determined by the mobility of exchange cations in theoretical deionized water and $\gamma$ is determined by the rate of increase of mobility from $\beta(1-\alpha)$ to $\beta$. Measurements of $\mathrm{Na}^{+}$self-diffusion coefficients (Richman \& Thomas 1956) confirm that the mobility of exchange ions increases with the fluid conductivity. Based on the model from eqs (6) and (7), with $\alpha, \beta$ and $\gamma$ being constant, Vinegar \& Waxman (1984) developed a complex conductivity model, where the quadrature conductivity, sensitive to 'delayed' conduction phenomena, accounts for accumulation (polarization) and relaxation of electrical charges at the interface between clay and pore water. The complex conductivity model by Vinegar \& Waxman (1984) was not validated for $Q_{\mathrm{v}}$ higher than $1 \mathrm{meq} \mathrm{mL} \mathrm{m}^{-1}$ (ratio charge to volume of fluid). They suggested that beyond this value, clay particles may be sufficiently connected to create a clay-conduction pathway, preventing any polarization to occur.

Finally, a model where the dominant conduction path shifts from the pore space to the mineral-water interface (the so-called electrical double layer 'EDL'), as salinity decreases, was suggested by Revil et al. (1998). In this model, the shift is responsible for the non-linear variations. This model was validated on the data set from Waxman \& Smits (1968), where the smectite content reaches 15 wt. per cent but was not tested on samples with higher smectite content.

\section{METHODS AND MATERIALS}

Eighty-eight samples were collected from a variety of lithologies, alteration facies and depths ranging from 12 to $700 \mathrm{~m}$, from four cored boreholes in the Krafla high-temperature area. The cores are cylinders with an average diameter of $4 \mathrm{~cm}$. The host rock of the cores is composed of successive layers of hyaloclastite, pillow breccias, vesicular lava, basaltic intrusion and more sporadically rhyolitic intrusions (Guðmundsson 1991; Jónsson et al. 2003; Gautason et al. 2007). The alteration level varies from fully/very altered samples (mainly tuff and hyaloclastite) to almost fresh samples (silicic extrusives and basaltic dykes). Electrical and porosity measurements were made on cylindrical plugs, with average length of $30 \mathrm{~mm}$ and average diameter of $25 \mathrm{~mm}$, taken from the core samples. The surrounding material of the cores were milled into powders (grain size $<40 \mu \mathrm{m}$ ) for CEC determination and XRD mineral quantification.

As the main objective of this study is to compare mineralogical and petrophysical properties of the rock, the representativeness of powder samples is important. Although core samples are taken from homogeneous geological layers, variability of the mineral content can be expected throughout different sections of the cylindrical plugs.

\subsection{Mineral quantification}

A quantitative phase analysis of the X-ray diffraction (XRD) patterns was carried by the Rietveld refinement method using the BGMN software (Taut et al. 1998). The powders were front-loaded onto the sample holder, using a razor blade to smoothen the surface, in order to avoid preferred orientations (see Bish \& Reynolds (1989)).

\subsection{Cation exchange capacity}

A protocol originally designed to measure the CEC on pure clay samples (Meier \& Kahr 1999) using Copper-triethyletetramine(II) 'Cu-trien' was chosen to measure the CEC in this study. Kaufhold \& Dohrmann (2003) suggested that the CEC of bentonites, measured by Cu-trien, is a measure of the smectite content in these bentonites. In samples containing zeolites, the CEC measurement may include a contribution from zeolites, but Meier \& Kahr (1999) showed that the CEC of pure clinoptinolite is reduced from $160 \mathrm{meq} / 100 \mathrm{~g}$, when measured with the classical ammonia method, to $5 \mathrm{meq} / 100 \mathrm{~g}$, when measured by $\mathrm{Cu}$-trien. Indeed the $\mathrm{Cu}$-trien molecule is too big to fit in the channels of zeolites, as opposed to the ammonia molecule. The $\mathrm{Cu}$-trien method is therefore adapted to measure the smectite content in altered volcanic samples. However, the low smectite content in our samples, compared to the two previously mentioned studies, required an adaptation of the protocol to obtain reliable CEC values. The adapted protocol developed by Lévy et al. (2016) was used for CEC measurements on the set of powders. The reacting solutions have a pH between 6.5 and 8.5 without using any $\mathrm{pH}$ buffer. This range is consistent with in situ $\mathrm{pH}$ values in most of Krafla area (Gudmundsson \& Arnórsson 2002). However, little pH dependency is expected here, due to the dominant contribution of the $\mathrm{pH}$-independent permanent CEC of smectite. 


\subsection{Porosity and density}

The porosity and density were determined on saturated core samples using the 'Triple Weighting' method: the plug mass was first measured on dry samples (dried at $60{ }^{\circ} \mathrm{C}$ in an oven for $48 \mathrm{hr}$ ), then measured on saturated samples, and finally measured in immersed conditions. The plugs were saturated with low-salinity (about $100 \mu \mathrm{S} \mathrm{cm}^{-1}$ ), degassed water after evacuating air-filled pores in a vacuum chamber.

\subsection{Electrical conductivity}

\subsubsection{Experimental device}

Electrical impedance was acquired over a large spectrum of frequencies (from $0.001-0.1 \mathrm{~Hz}$ to $1 \mathrm{MHz}$ ) using a Solartron 1260 impedance meter. Two different experimental set-ups were used to measure the electrical conductivity: two-electrode set-up, where the sample is sandwiched between two metallic electrodes acting as current and voltage electrodes and a four-electrode set-up [following Vinegar \& Waxman (1984)], where the voltage and current electrodes are separated. In the four-electrode set-up, Nickel electrodes are used to inject the current and non-polarizable $\mathrm{Ag} / \mathrm{AgCl}$ electrodes are used for voltage measurement. The contact between current electrodes and the sample is ensured by a fluid layer situated in-between ( $5 \mathrm{~mm}$ thick at each side). The fluid layer, which contains the same fluid as the sample, is responsible for an additional resistance, in series with the sample impedance. This additional resistance has been quantified as a function of fluid conductivity using several tubular samples of different lengths, similarly to the approach of Waxman \& Smits (1968). Although the four-electrode set-up improves the quality of the conductivity spectra, especially below $10 \mathrm{kHz}$, where effects of electrode polarization are removed, the values at $1 \mathrm{kHz}$ for both set-ups are comparable [Figs 3(a) and (b)]. Indeed, from eq. (1), it can be seen that the real part of the impedance $Z^{\prime}$ is close to its modulus when $\theta$ is low. The relative difference between $Z^{\prime}$ and $|Z|$ is less than 2 per cent when $\theta$ is less than 200 $\mathrm{mrad}$, which is the maximum reached by the phase angle at $1 \mathrm{kHz}$ on our samples. Therefore, we can assume that the in-phase conductivity at $1 \mathrm{kHz}$ is negligibly affected by the phase and thus by polarization effects. In the following, we focus on the relationship between electrical conduction and smectite content and use only the in-phase conductivity data at $1 \mathrm{kHz}$.

\subsubsection{Experimental procedure}

Each core was saturated after evacuating air-filled pores in a vacuum chamber with electrolytes of different salinities, using aqueous $\mathrm{NaCl}$ solutions at different concentrations. After changing the salinity of the pore fluid, all the samples were kept together in the same fluid for at least one month in order to achieve rock/fluid equilibrium. Glover (2016) showed that the actual fluid conductivity in a sample can be up to 30 per cent higher than the conductivity of the soaking fluid for fluid conductivities between 0.01 and $0.1 \mathrm{~S} \mathrm{~m}^{-1}$, up to 15 per cent higher for fluid conductivities between 0.1 and $1 \mathrm{~S} \mathrm{~m}^{-1}$, and up to 5 per cent lower for fluid conductivities higher than $1 \mathrm{~S} \mathrm{~m}^{-1}$, due to dissolution/precipitation reactions or incomplete saturation/homogenization. We use these percentages to calculate an uncertainty on the conductivity of the fluid saturating the sample.

Two groups of samples were investigated. For Group 1, three series of measurements were performed in order to test the reproducibility of the measurements and possible hysteresis, following Waxman \& Smits (1968): (i) Run 1: fluid conductivity increasing from 0.02 to $11.5 \mathrm{~S}$ $\mathrm{m}^{-1}$, (ii) Run 2: fluid conductivity decreasing from 0.5 to $0.02 \mathrm{~S} \mathrm{~m}^{-1}$ and (iii) Run 3: fluid conductivity increasing from 0.02 to $5.33 \mathrm{~S} \mathrm{~m}^{-1}$. For Group 2, one series of measurement was performed between 0.05 and $11.1 \mathrm{~S} \mathrm{~m}^{-1}$. The fluid conductivity in the Krafla geothermal system is about $0.07 \mathrm{~S} \mathrm{~m}^{-1}$ (Flóvenz et al. 2005), but covering a large range of fluid conductivities is necessary to analyse the relative influence of pore fluid and minerals on the bulk conductivity. For both groups, the data set from Run 1 is the richest and is therefore used in the rest of the study for both groups of samples (details in Table 2).

\section{RESULTS}

The measurements of CEC, porosity and mineralogy distribution are given in Table B1.

\subsection{The relation between CEC and the smectite content}

In Fig. 4, we compare the CEC using Cu-trien and the smectite content from XRD quantitative analysis using the Rietveld structure models. Due to the complexity of Rietveld refinements when several types of clays are involved (Bruno Lanson, private communication, 2017), the XRD quantification of smectite content was only made for samples without chlorite. Additional measurements allowed us to verify the absence of contribution to the CEC from other mineral phases. The contribution of heulandites in our CEC measurements was assessed by a Cu-trien back titration of the exact same heulandites samples as used by Fridriksson et al. (2004). The CEC measured for natural heulandite and Na-saturated heulandite are, respectively, $0.5 \pm 0.2$ and $1.5 \pm 0.2 \mathrm{meq} / 100 \mathrm{~g}$, that is $0.1-0.3$ per cent of the total CEC measured by Fridriksson et al. (2004). Given that other families of zeolites (e.g. laumontite) do not have the ability to exchange cations in their channels at all (Dyer 1991), we conclude that the contribution of zeolites in our samples is negligible. The negligible contribution of high-temperature alteration minerals, including chlorite, to the CEC is shown in Table 3. We consider that the contribution of interstratified smectite/chlorite 


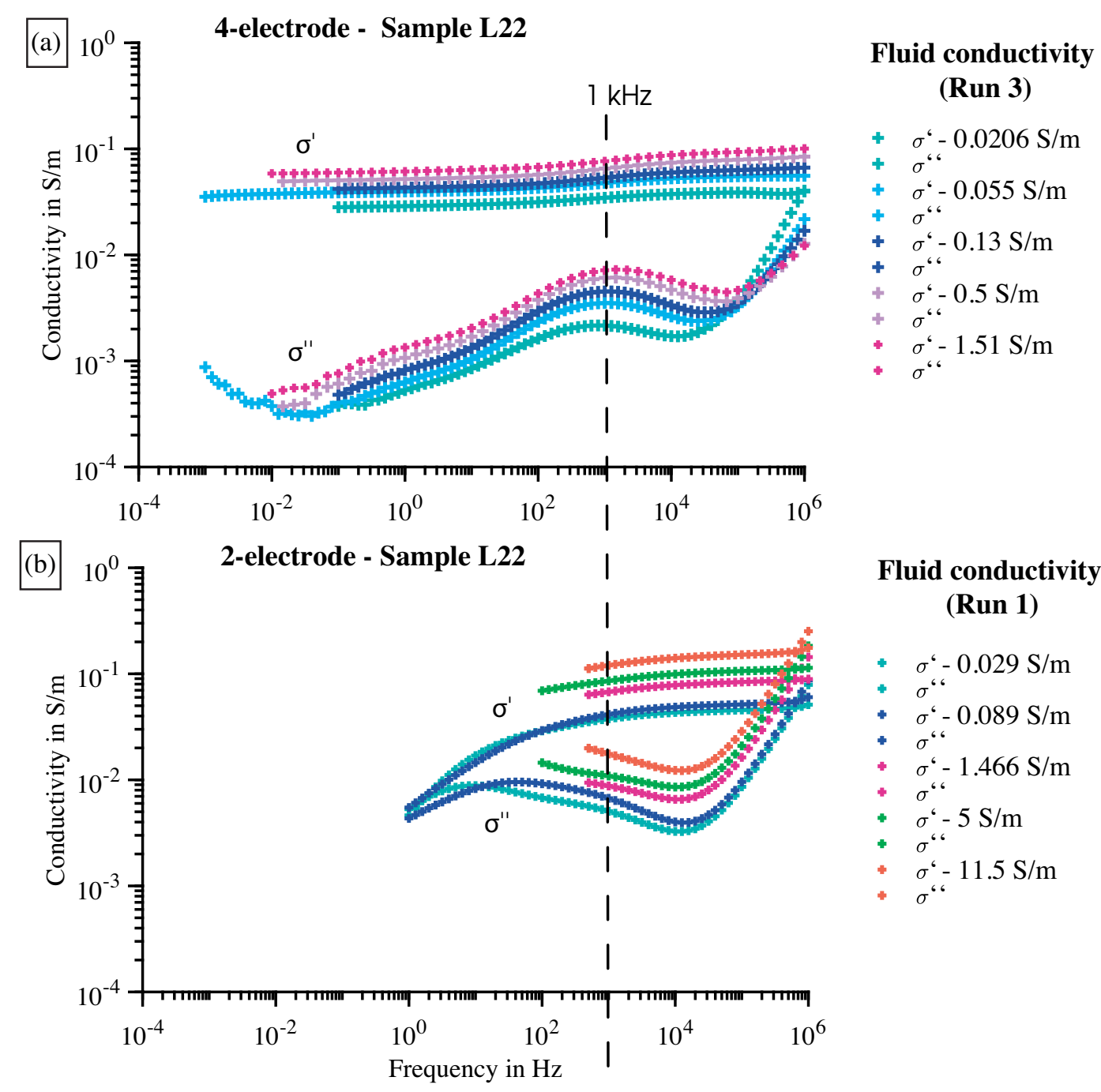

Figure 3. In-phase $\left(\sigma^{\prime}\right)$ and quadrature $\left(\sigma^{\prime \prime}\right)$ conductivity spectra of sample L22 for different fluid conductivities. (a) Four-electrode measurements and (b) two-electrode measurements. The data quality is much improved with the four-electrode set-up but the in-phase conductivities at $1 \mathrm{kHz}$ measured by two and four electrodes are comparable at a given fluid conductivity. Only few measurements were available in Run 1 for the four-electrode set-up, therefore the measurements from Run 3 are shown here.

Table 2. Fluid conductivity in Run 1 for Group 1 (Samples L02-L103) and Group 2 (Samples L104-L123).

\begin{tabular}{|c|c|c|c|}
\hline \multicolumn{2}{|c|}{ Group1 Run1 } & \multicolumn{2}{|c|}{ Group2 Run1 } \\
\hline $\mathrm{S} \mathrm{m}^{-1}$ & $\mathrm{~S} \mathrm{~m}^{-1}$ & $\mathrm{~S} \mathrm{~m}^{-1}$ & $\mathrm{~S} \mathrm{~m}^{-1}$ \\
\hline \multirow[t]{2}{*}{0.0895} & & 0.1 & 0.1 \\
\hline & 0.51 & 0.5 & 0.5 \\
\hline 1.466 & 1.466 & 1.5 & 1.5 \\
\hline
\end{tabular}

minerals (e.g. corrensite) to the CEC is directly correlated to their smectite fraction, based on the results of Hower \& Mowatt (1966) with smectite/illite mixed-layers series and the fact that the CEC of pure chlorite is lower than the CEC of illite. We finally assume that the CEC of other minerals present in the samples, and not mentioned in this section, is close to 0 .

The linear fit shown in Fig. 4 has a slope $\mathrm{CEC}_{0}=91 \mathrm{meq} / 100 \mathrm{~g}$ and a regression coefficient $R^{2}=0.9457$. We consider that CEC $\mathrm{C}_{0}$ is the CEC of pure smectite in our samples, which is consistent with the range $80-120 \mathrm{meq} / 100 \mathrm{~g}$ presented in Table 1 . In what follows, we use the following equation to calculate the smectite weight content in all samples:

$\frac{\mathrm{CEC}}{\mathrm{CEC}_{0}}=\frac{m_{\text {smectite }}}{m_{\mathrm{g}}}$, 


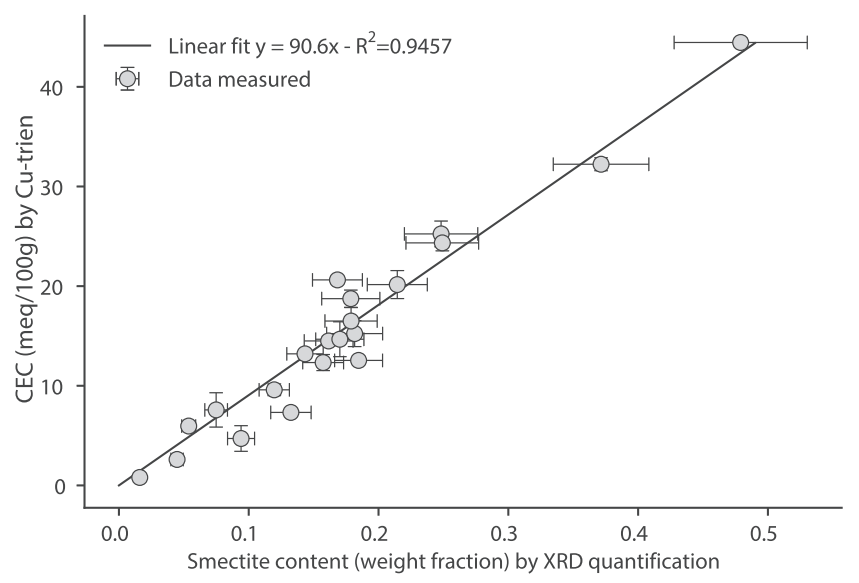

Figure 4. Correlation between CEC, measured using Cu-trien, and smectite content determined by XRD for samples with smectite as the only clay mineral. Here, the unit meq/100 $\mathrm{g}$ is used for comparison with reference values listed in Table 1 . The SI unit is however $\mathrm{C} \mathrm{kg}^{-1}$ with $1 \mathrm{meq} / 100 \mathrm{~g}=964.85 \mathrm{C}$ kg ${ }^{-1}$.

Table 3. CEC, measured by Cu-trien, of samples with high-temperature alteration.

\begin{tabular}{lc}
\hline Sample & CEC in meq/100g \\
\hline L49 & $0.2 \pm 0.2$ \\
L50 & $0.25 \pm 0.25$ \\
L47 & $0.35 \pm 0.05$ \\
L48 & $0.35 \pm 0.35$ \\
L46a & $0.45 \pm 0.35$ \\
L67a & $0.45 \pm 0.4$ \\
\hline
\end{tabular}

Notes: Chlorite is the only clay mineral in these samples (see also Table B1). Based on XRD mineral quantification of the chlorite phase, we calculate that the $\mathrm{CEC}$ of pure chlorite in the samples is lower than $6 \pm 4 \mathrm{meq} / 100 \mathrm{~g}$.

where $m_{\text {smectite }}$ and $m_{\mathrm{g}}$ are the mass of smectite and the total mass of solid (the 'grain' mass) in the sample, respectively.

\subsection{Analysis of electrical measurements}

Electrical conductivity spectra were obtained for each sample saturated with six distinct saline solutions, with both the two-electrode and four-electrode set-ups, as shown in Fig. 3. Only real conductivity values at $1 \mathrm{kHz}$ are used here and available as Supporting Information.

Reliable electrical measurements are inferred for 76 of the total 88 samples. Twelve samples show unreliable electrical measurements: L12a, L30, L35, L76, L81, L85, L104, L106, L108, L111, L112 and L117 (see four examples in Fig. A2). Their porosity ranges from 1 to 10 per cent (Table B1) and unreliable results are attributed to incomplete saturation of pores or lack of fluid/rock equilibrium (Glover 2016).

From Runs 1 to 3, the bulk conductivity increases up to 50 per cent at a given fluid conductivity for samples with high smectite content (Fig. 5). Non-repeatable measurements were also observed by Waxman \& Smits (1968) until seven different saturations at high fluid conductivity were made. These authors suggested a very slow rehydration of montmorillonite after complete dehydration (following the encasing in epoxy resin) as a possible explanation. We suggest that the increased conductivity after repeated flushing with $\mathrm{NaCl}$ may also be due to a progressive replacement of exchange cations associated to smectite: $\mathrm{Na}^{+}$replaces $\mathrm{Ca}^{2+}$ naturally present. Since $\mathrm{Na}^{+}$is more mobile than $\mathrm{Ca}^{2+}$, the electrical conductivity associated with smectite would increase after this replacement. However, specific measurements are needed to confirm this hypothesis.

Non-linear variations of the bulk conductivity with the fluid conductivity are observed for samples with high smectite content and are preserved from Runs 1 to 3 [Figs 5(c) and (d)], indicating that they are not due to a transient behaviour in Run 1. These non-linear variations were also observed by Waxman \& Smits (1968) even after successive saturations allowing to reach a steady state. In what follows, data from Run 1 only are used.

A new model accounting for the observed non-linear behaviour and valid for our whole sample set, containing 0 to 50 wt per cent smectite, is needed. Reciprocally, our data set is useful to test existing and new models. First, the linear version of Waxman \& Smits (1968) model is used to analyse the measurements of in-phase conductivity. This model (eq. 6 with B independent of the fluid conductivity), suggested by Rink \& Schopper (1974), was used by Flóvenz et al. (1985), Pezard (1990), Flóvenz et al. (2005) as well as Revil et al. (2017a). The two constant parameters $a_{0}=1 / F$ and $c_{0}=B Q_{\mathrm{v}} / F$ are retrieved by least-squares fitting of eq. (9) ('Linear'):

$\sigma_{\text {bulk }}=a_{0} \sigma_{\mathrm{w}}+c_{0}$,

We observe in Fig. 6 that eq. (9) fits well samples with low smectite content, but important deviations are observed for samples with high smectite content. About 30 per cent of the samples have high smectite content and are not correctly fitted with eq. (9). 
L48

(a)

L93

(b)
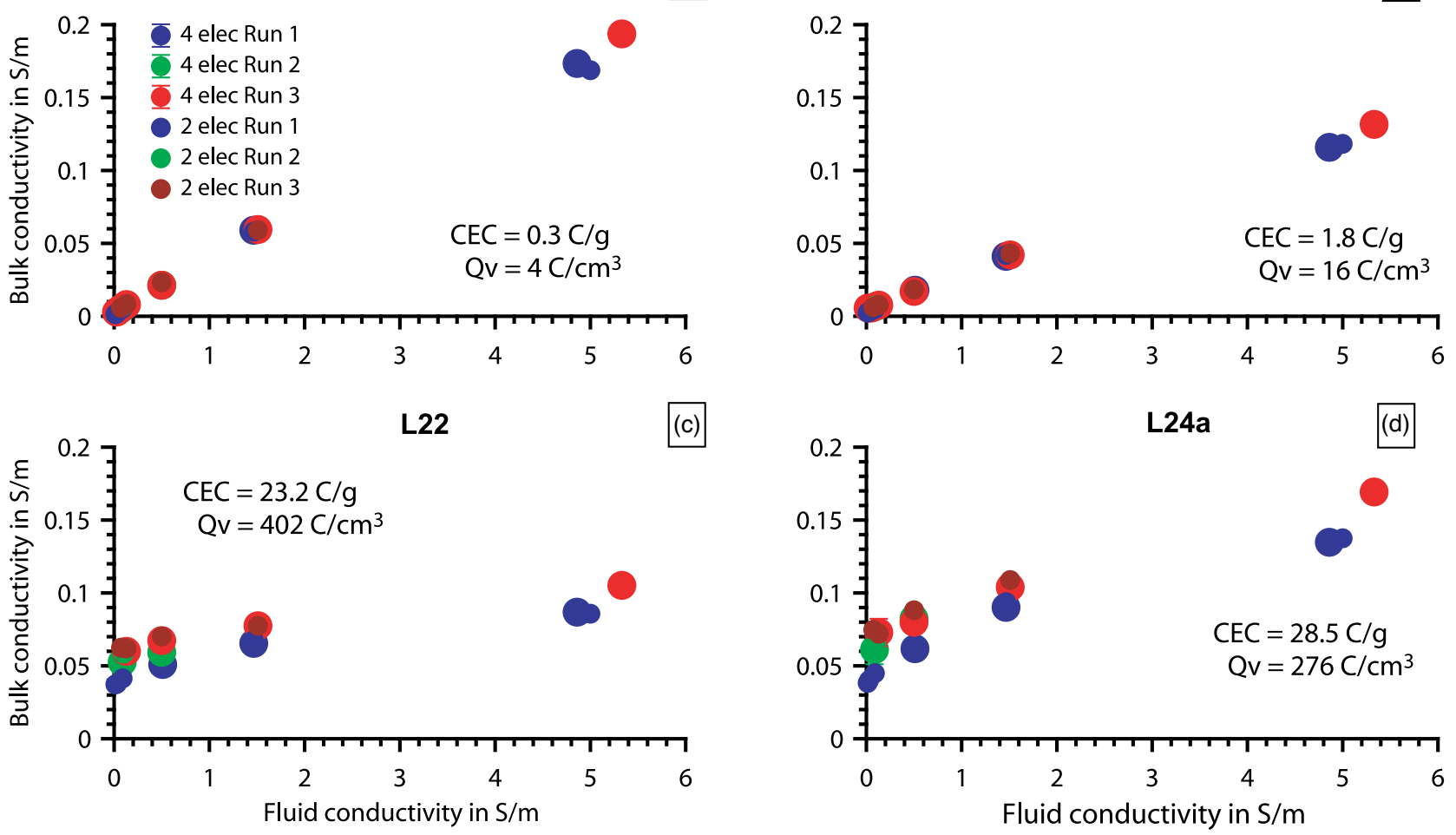

Figure 5. Results from electrical measurements at $1 \mathrm{kHz}$ for four samples with increasing CEC. Panels (a), (b), (c) and (d) show results for samples L48, L93, L22 and L24a, respectively. For samples with high CEC (high smectite content), the bulk conductivity increases from one run to the following.
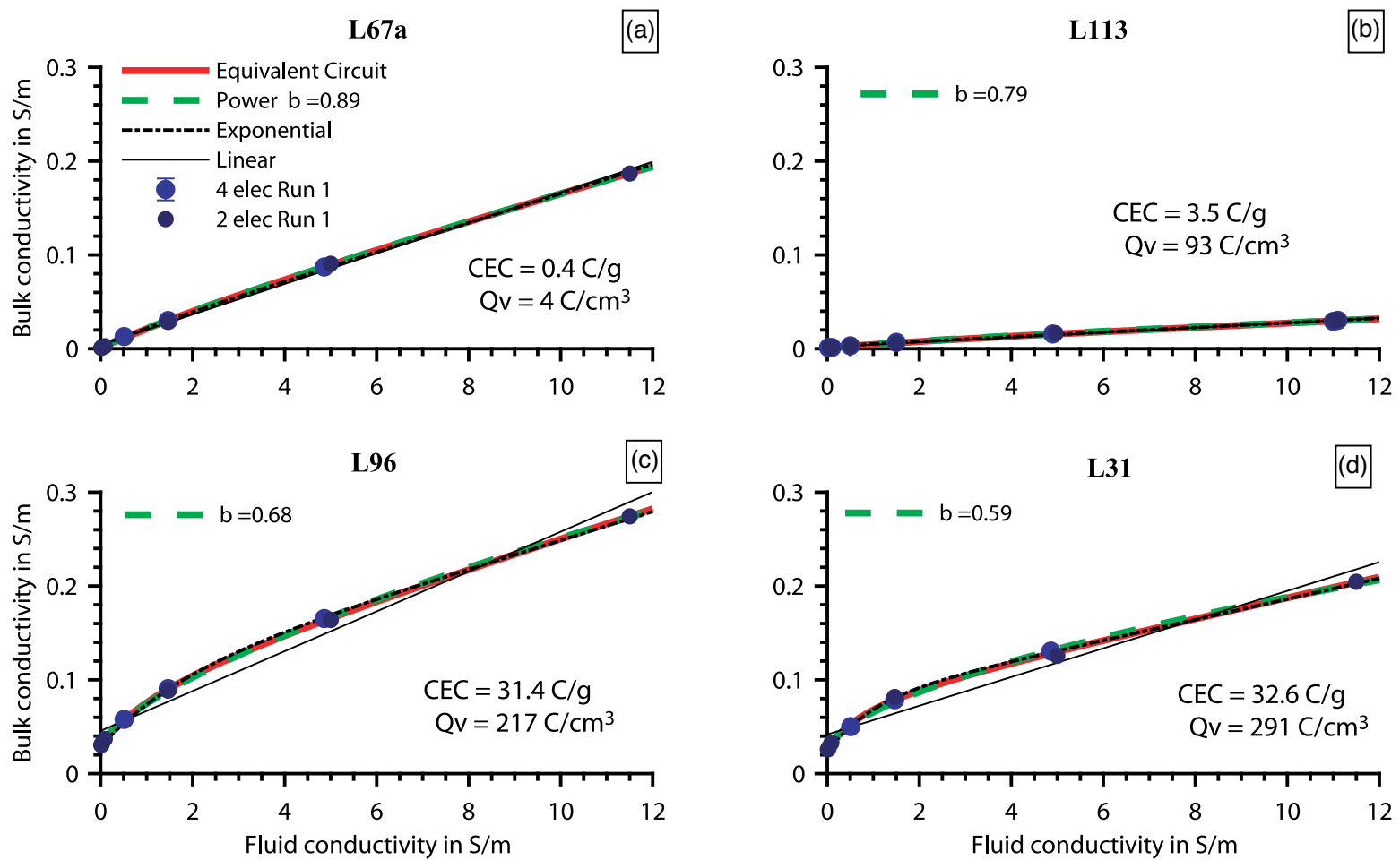

Figure 6. Observed bulk conductivity at $1 \mathrm{kHz}$ versus fluid conductivity for four samples with increasing $Q_{\mathrm{v}}$. Panels (a), (b), (c) and (d) show results for samples L67a, L113, L96 and L22, respectively. Three non-linear functions are used to fit the data, in addition to the classical linear function: Power, Exponential and Equivalent Circuit. The Power and Equivalent circuit models are overlapping for the four samples. Data shown in the figure and used for the fit are from Run 1 only (both two-electrode and four-electrode). The in situ fluid conductivity in Krafla is below $0.1 \mathrm{~S} \mathrm{~m}^{-1}$, in the steepest part of the curves. 


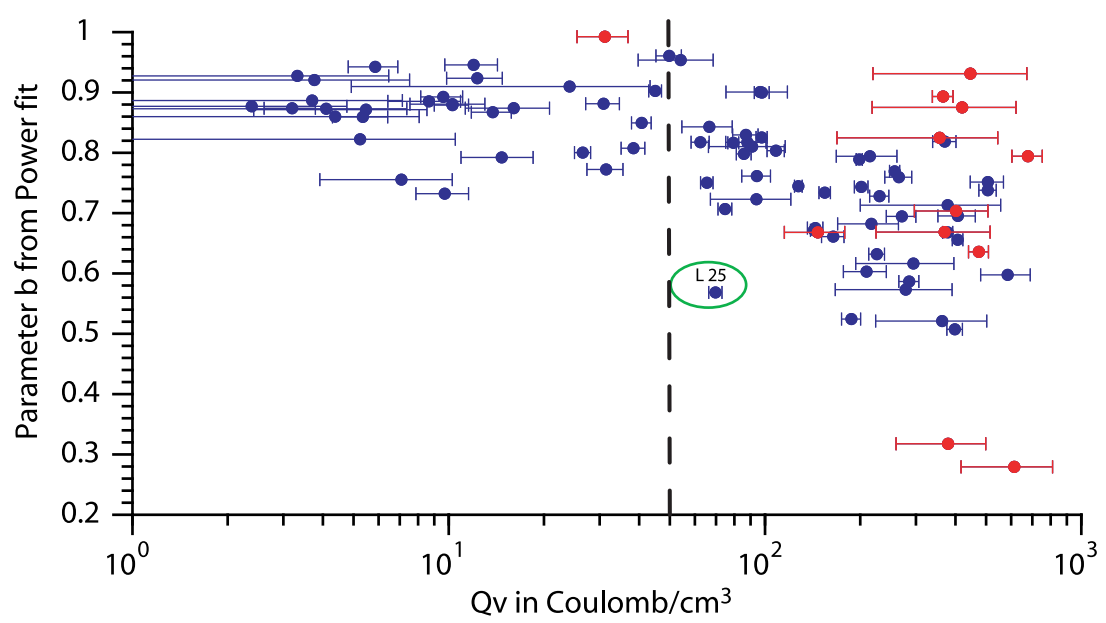

Figure 7. Comparison of the parameter $b$ derived from the fit Power $\left(\sigma_{\text {bulk }}=\mathrm{a} \sigma_{\mathrm{w}}{ }^{\mathrm{b}}+\mathrm{c}\right.$ ) with $Q_{\mathrm{v}}$. The dotted line marks the threshold value of $\mathrm{Q}_{\mathrm{v}}$ where $b$ starts to decrease significantly from 1 (non-linear behaviour). The red data points correspond to the 12 samples with unreliable electrical data.

Next, the full version of Waxman \& Smits (1968) model is used (eq. 10):

$\sigma_{\text {bulk }}=\mathrm{a}_{1} \sigma_{\mathrm{w}}+\mathrm{c}_{1}\left(1-0.7 e^{-\frac{\sigma_{\mathrm{w}}}{\gamma}}\right)$,

by combining eqs (6) and (7), with $a_{1}=1 / F, c_{1}=\beta Q_{\mathrm{v}}$ and using $\alpha$ fixed to the average value 0.7 . This equation ('Exponential') provides improved fit to the data (Fig. 6). However, the $\gamma$ parameter does not show any dependence to the smectite content.

Finally, eq. (11) ('Power') is developed by adding an exponent to eq. (9) :

$\sigma_{\text {bulk }}=\mathrm{a} \sigma_{\mathrm{w}}^{\mathrm{b}}+\mathrm{c}$

This is the closest non-linear function to the linear model. The physical meaning of $a$ and $c$ is similar to that of $a_{0}$ and $c_{0}$. Eq. (11) allows an improved fit to the data (Fig. 6) and the $b$ parameter depends on the smectite content: it is close to 1 for samples with low $Q_{\mathrm{v}}$ and down to 0.4 for samples with high $Q_{\mathrm{v}}$ (Fig. 7).

The fitting parameters for Linear, Exponential and Power fits are listed in Table C1. The parameters $a, a_{0}$ and $a_{1}$ follow an exponential relationship with the porosity. Similarly to the so-called 'formation factor' $F$, the inverse of these parameters can be approximated by the original Archie's law $F=\phi^{-m}$ (Archie 1942) or by its modified form $F=A \phi^{-m}$ (Winsauer et al. 1952). A discussion of these two empirical functions is given in Glover (2016). Both functions do approximate the relationship between $1 / a$ and $\phi$ (Fig. C1). Parameters $c, c_{0}$ and $c_{1}$ increase linearly with $Q_{\mathrm{v}} / F$, similarly to the 'EDL conduction' (more details in Fig. C2).

We also validated eq. (11) using electrical measurements on shaly sands by Waxman \& Smits (1968), on altered igneous rock from Iceland by Flóvenz et al. (2005) and on igneous rock from Hawaii with low alteration stage by Revil et al. (2017a). For a given porosity, the shaly sandstones have a lower formation factor than igneous rocks $[$ Fig. $8(\mathrm{a})]$ and for a given value of $Q_{\mathrm{v}} / F$, the shaly sandstones have a higher conductivity 'associated to clay' than igneous rocks [Fig. 8(c)]. These two differences between shaly sandstones and igneous rocks are possibly due to a better connectivity of both pore water and clays in permeable sandstones. Given the large scattering observed, the parameter $c$ cannot be accurately predicted with the parameter $Q_{\mathrm{v}} / F$. The four data sets show the same dependence of $b$ upon $Q_{\mathrm{v}}$ [Fig. 8(b)]; this confirms the role of smectite in the non-linear behaviours.

In the next section, we analyse further the dependence of the $b$ parameter on the smectite content and build a phenomenological model which can explain the non-linear variations of bulk conductivity with fluid conductivity, as well as the dependence of this non-linearity upon the smectite content.

\subsection{From a new fitting function to a phenomenological model}

Fig. 7 highlights a general dependence of the $b$ parameter on $Q_{\mathrm{v}}$. Parameter $b$ is close to $0.8-0.9$ for $Q_{\mathrm{v}}<50 \mathrm{C} \mathrm{cm}^{-3}$ and significantly decreases for $Q_{\mathrm{v}}>50 \mathrm{C} \mathrm{cm}^{-3}$. We calculate the corresponding volumetric ratio between smectite sheets and pore fluid in the rock by combining eqs (5) and (8) into eq. (12):

$$
\begin{aligned}
Q_{\mathrm{v}} & =\frac{(1-\phi)}{\phi} \mathrm{CEC}_{0} \rho_{\mathrm{g}} \frac{m_{\text {smectite }}}{m_{\text {solid }}}=\frac{(1-\phi)}{\phi} \mathrm{CEC}_{0} \rho_{\text {smec }} \frac{V_{\text {smectite }}}{V_{\text {solid }}} \\
& =\mathrm{CEC}_{0} \rho_{\text {smec }} \frac{V_{\text {smectite }}}{V_{\text {fluid }}},
\end{aligned}
$$

where $\rho_{\text {smec }}$ is the average density of smectite minerals and $\mathrm{CEC}_{0} \rho_{\mathrm{smec}}=202 \mathrm{C} \mathrm{cm}^{-3}$. This leads to a smectite/fluid ratio of $\frac{V_{\text {smectite }}}{V_{\text {fluid }}}=$ $\frac{Q_{\mathrm{v}}}{\mathrm{CEC}_{0} \rho_{\text {smec }}}=50 / 202=25$ per cent. We interpret this ratio as a threshold beyond which a conduction path across the solid becomes important 


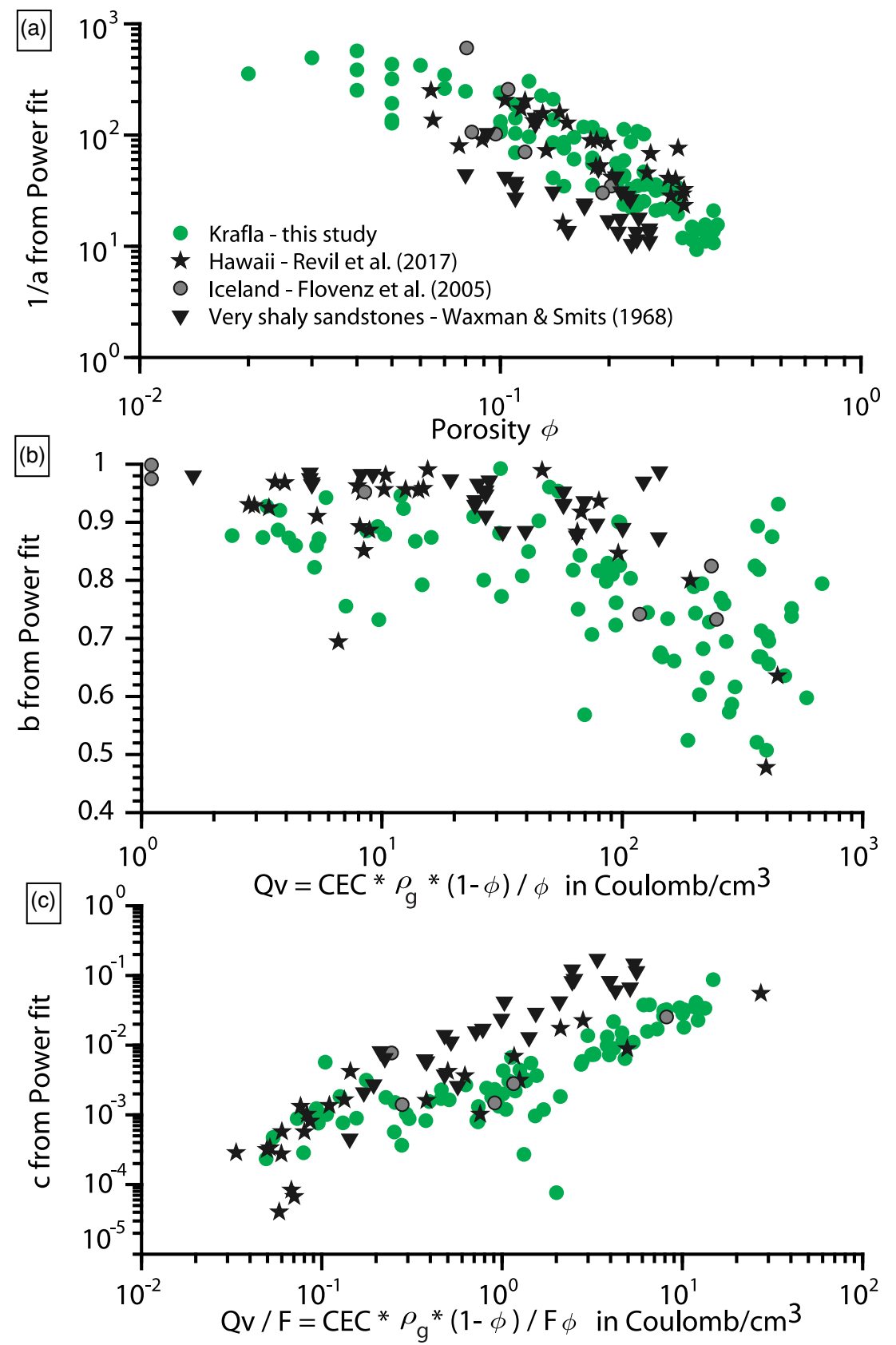

Figure 8. Comparison of the results with three other studies. The three parameters derived from the Power fit are displayed respectively in (a), (b) and (c).

compared to the conduction path across the fluid. This path only exists when a certain critical amount of smectite is present. The amount needed is a percolation threshold, similarly to the minimum porosity needed for water to percolate throughout an heterogeneous media (Gueguen \& Dienes 1989). This concept extends the idea developed by Douglas (1981) and Flóvenz et al. (1985) that continuity of smectite exists and can permit the volume conduction of smectite sheets. According to Vinegar \& Waxman (1984), eq. (5) is validated by their complex electrical measurements only for reservoir sands where the ratio between electrical charges and pore fluid $Q_{\mathrm{v}}$ remains lower than 1 meq $\mathrm{mL}^{-1}=96 \mathrm{C} \mathrm{cm}^{-3}$. This threshold value is close to the value determined from Fig. 7. These authors suggest that for $Q_{\mathrm{v}}$ higher than $1 \mathrm{meq}$ $\mathrm{mL}^{-1}$, the clay-free zones become so short that no polarization occurs and a continuous clay conduction path is shaped.

Based on these observations, we present an 'Equivalent Circuit' function, corresponding to a new phenomenological model. Using an equivalent circuit representation of electrical conduction [Fig. 9(a)], the above-mentioned conduction path corresponds to an additional branch across the solid (pathway no. 3), added in parallel to the classical circuit (see e.g. Vinegar \& Waxman 1984) composed of electrolytic conduction (pathway no. 1) in parallel to EDL conduction (pathway no. 2). The bulk conductivity corresponding to the three pathways in parallel is then given by:

$\sigma_{\text {bulk }}=\frac{\sigma_{\mathrm{w}}}{F}+\sigma_{\mathrm{EDL}-\text { interface }}+\sigma_{\text {intra-solid }}$ 
(a)

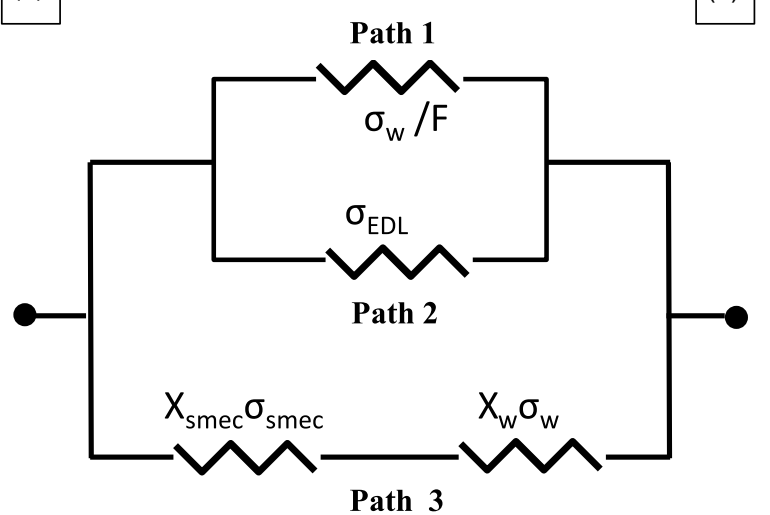

(b)

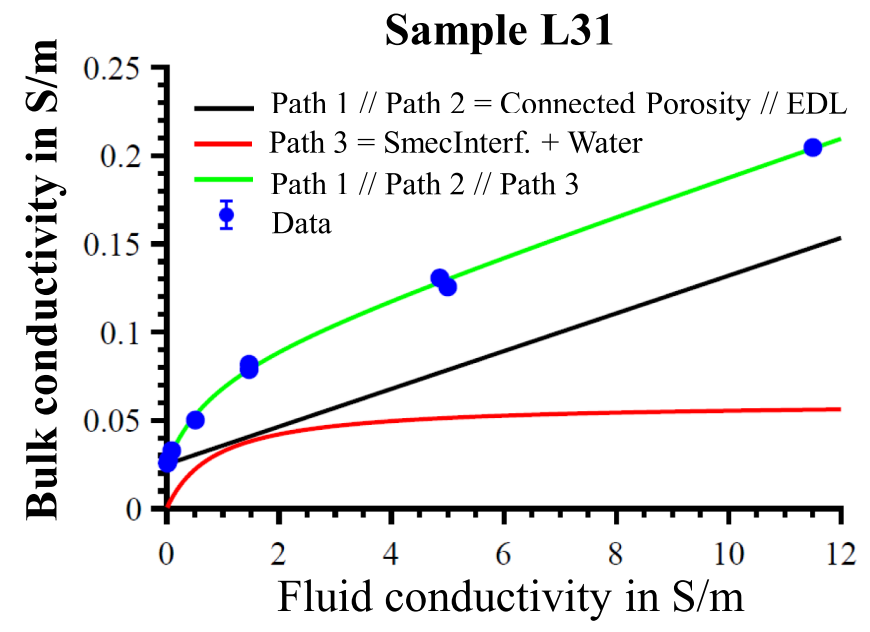

(c) FREE ELECTROLYTE
SOLID

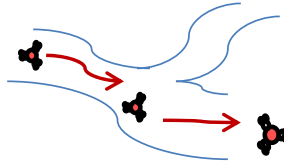

$\longmapsto 10 \mu \mathrm{m}$

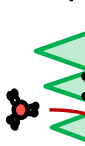
(no free electrolyte)

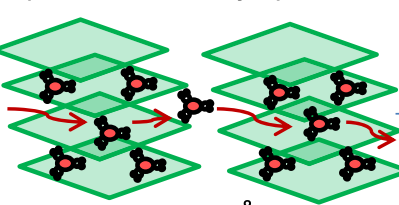

$\longmapsto 10 \AA$

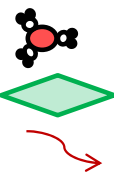

$\mathrm{Na}^{+}$cation surrounded by 3 water molecules

T-O-T sheets of smectite, represented by a plane Ionic electrical conduction

FREE ELECTROLYTE
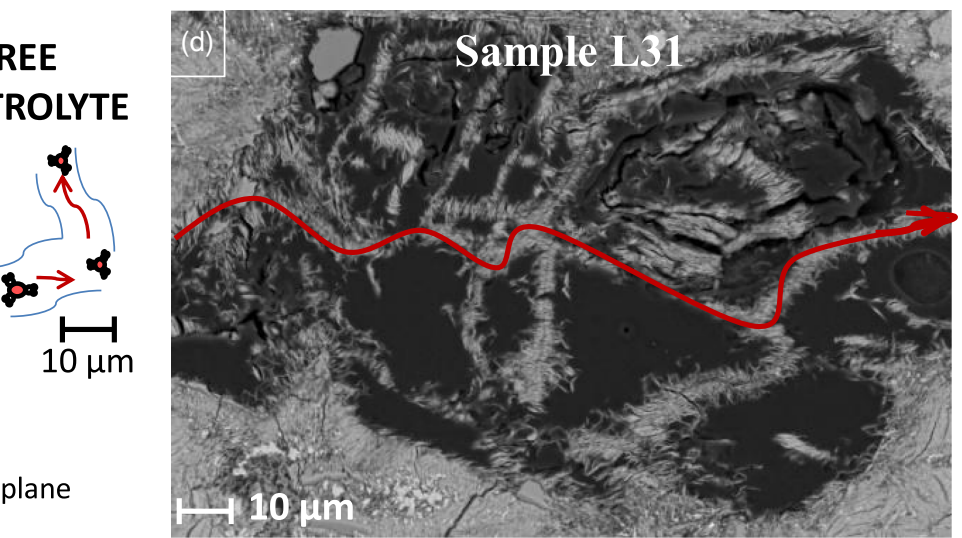

Figure 9. Conceptual model for electrical conduction in smectite-rich rock, involving an additional conduction pathway. (a) Equivalent circuit including the new conduction path as a parallel branch to the classical circuit; (b) fitted bulk conductivity, using the Equivalent Circuit model for sample L31, with best-fitting parameters: $F=94, \sigma_{\mathrm{EDL}}=0.025 \mathrm{~S} \mathrm{~m}^{-1}, X_{\mathrm{W}}=7$ per cent and $\sigma_{\text {smec }}=0.18 \mathrm{~S} \mathrm{~m}^{-1}$ (the volumetric content of smectite sheets $X_{\mathrm{smec}}=34$ per cent is used, based on CEC and porosity measurements). The decomposition of the fitted conductivity into its linear component (fluid in the connected porosity, in parallel to EDL - black linear curve) and its non-linear component (smectite interfoliar spaces, in series with water outside the connected porosity-red non-linear curve) is also given; (c) schematic view of ionic conduction through interfoliar spaces of smectite and (d) SEM image of 'connected smectite' in the sample L31. The red line shows continuous smectite over $100 \mu \mathrm{m}$.

The conduction path across the solid need not to be continuous throughout the whole sample: provided that charge carriers are ions, this conduction path can be bridged by electrolytic conduction. The intra-solid conductivity, represented by solid and electrolyte in series, increases non-linearly with the electrolytic conductivity:

$\sigma_{\text {intra-solid }}=\frac{1}{\frac{1}{X_{\mathrm{w}} \sigma_{\mathrm{w}}}+\frac{1}{X_{\mathrm{sol}} \sigma_{\mathrm{sol}}}}$

Here, $X_{\text {sol }}$ is the fraction of solid contributing to intra-solid conduction, $\sigma_{\mathrm{sol}}$ is the intrisic conduction of the solid and $X_{\mathrm{w}}$ is the fraction of electrolyte bridging solid conduction. The quantity of water accounted in $X_{\mathrm{w}}$ is part of pathway no. 3 but not part of pathway no. 1 . Indeed the cations conducting electricity in the connected porosity are already occupied by pathway no. 1 and cannot conduct electricity in the pathway no. 3 . We name the parameter $\mathrm{F}^{\prime}=1 / X_{\mathrm{w}}$ the formation factor of the intra-solid pathway, by analogy with the formation factor of the connected porosity (pathway no. 1).

Fig. 9(b) shows that eq. (15), which is a reformulation of eqs (13) and (14) represents well the behaviour observed in sample L31 (containing 32 wt per cent of smectite).

$\sigma_{\text {bulk }}=a_{2} \sigma_{\mathrm{w}}+b_{2}+\frac{\mathrm{c}_{2} \sigma_{\mathrm{w}}}{1+\frac{\mathrm{c}_{2}}{\mathrm{~d}_{2}} \sigma_{\mathrm{w}}}$

Here, $\mathrm{a}_{2}=1 / \mathrm{F}, b_{2}=\sigma_{\mathrm{EDL}}, c_{2}=X_{\mathrm{w}}=1 / \mathrm{F}^{\prime}$ and $\mathrm{d}_{2}=X_{\mathrm{sol}} \sigma_{\mathrm{sol}}$.

The bulk-fluid conductivity variations of the 76 samples with reliable electrical data were correctly fitted using eq. (15), named 'Equivalent circuit' (Fig. 6). The four fitting parameters can be found in Table $\mathrm{C} 1$ for the whole sample set. While $\mathrm{a}_{2}$ follows an exponential relationship to porosity, clear correlations between $b_{2}, c_{2}$ and $d_{2}$ and other parameters, such as CEC, porosity and $Q_{\mathrm{v}}$ are missing. 
Despite this ambiguity about new parameters, we interpret the additional conduction as occurring through connected interfoliar spaces of smectite. Indeed this intra-solid conduction must respect three characteristics: (1) the charges transferred are ions to ensure that saline water can bridge the gaps, (2) high smectite content is required because the non-linear feature depends on the smectite content of the solid phase (Fig. 7) and (3) the free electrolyte path is interrupted when the solid is encountered because two distinct conductors are in series in the model. This additional path involves ions transfer without electrolyte. It therefore differs from EDL conduction. Moreover, the increasing mobility of exchange ions with salinity introduced by Waxman \& Smits (1968) in the Exponential function does not describe a dependence of the non-linear effect to the smectite content.

Cations transfer through connected interfoliar spaces of smectite particles matches the three characteristics mentioned above, as illustrated in Fig. 9(c). An example of smectite connectivity over a long distance is shown in Fig. 9(d). We therefore name the intra-solid conduction 'interfoliar conduction' in what follows. Considering now that the solid fraction contributing to solid conduction is comprised of smectite interfoliar spaces, we have $X_{\text {sol }}=X_{\text {smec }}$, the volume fraction of smectite in the bulk rock which is connected to either smectite or water. The same smectite particle can contribute in parallel to EDL conduction (pathway no. 2, external edges involved) and to intra-smectite conduction (pathway no. 3, interfoliar spaces involved). Pathway no. 3 includes however more smectite particles than pathway no. 2: smectite in sealed fractures, altered glass or in replacement of plagioclases can only be part of pathway no. 3. If all smectite particles are connected, $X_{\text {smec }}=\frac{V_{\text {smectite }}}{V_{\text {tot }}}=\frac{\operatorname{CEC} \rho \mathrm{g}_{\mathrm{g}}(1-\phi)}{\operatorname{CEC}_{0} \rho_{\text {smec }}}$. Finally, $\sigma_{\text {sol }}=\sigma_{\text {smec }}$ is the intrisic conductivity of smectite interfoliar spaces.

Given the shape of eq. (15), interfoliar conduction is more important than fluid conduction when $\sigma_{\mathrm{w}}<\left|X_{\text {smec }}\left(F^{\prime}-F\right) \sigma_{\text {smec }}\right|$, if $F^{\prime}<F$ (which is the case for most samples containing smectite). The values taken by this threshold vary between 0.1 and $10 \mathrm{~S} \mathrm{~m}^{-1}$ and increase with the smectite content. Therefore, for typical fluids found in geothermal systems, interfoliar conduction dominates in rocks presenting sufficient smectite connectivity $\left(F^{\prime}<F\right)$.

This phenomenological model is a step forward to understand conduction processes in rocks where both the pore fluid and smectite sheets contribute to the total conduction along different pathways.

\section{DISCUSSION}

\subsection{Process of electrical conduction in smectite}

Previous studies (Waxman \& Smits 1968; Flóvenz et al. 2005; Revil et al. 2017a) emphasized that the CEC (or the $Q_{\mathrm{v}}$ ) is a key parameter controlling the electrical conductivity of shaly sands and altered volcanic rocks, which is confirmed here. We showed that the CEC in altered volcanic rocks is mainly caused by cation exchanges associated with smectite. We explained that the CEC of smectite includes more than 70 per cent of interfoliar sites. A conduction process associated to mobile cations within interfoliar spaces was therefore considered to explain the high conductivity of smectite-rich samples, and a phenomenological model presented. This model suggests that a third pathway exists for ionic conduction, in addition to pore fluid and EDL conductions: intra-solid conduction through connected interfoliar spaces of smectite in the solid matrix. This model explains the non-linear behaviour found in smectite-rich samples and allows a better representation of experimental data than models having only pore fluid and EDL conductions. Interfoliar conduction does not involve a free electrolyte, but mobile cations hydrated by $2-3$ water shells. Therefore, interfoliar conduction cannot be included in EDL models, which require a free electrolyte and only account for cations on external faces of phyllosilicates [see Lyklema (2001) and Leroy \& Revil (2009)].

Given the small crystal size of phyllosilicates such as smectite and illite, the external specific surface area (SSA) of these minerals is higher than in better-crystallized minerals. According to EDL models, the high CEC, and therefore the high conductivity of clay-rich materials, is explained solely by the high external SSA of clays (see e.g. Leroy \& Revil 2009; Revil et al. 2017b). However, since a large part of the CEC of smectite is located in the interlayer spaces (internal SSA), not on its external surface (Lagaly 1981), the CEC and external SSA of smectite are not proportional [see e.g. Diamond \& Kinter (1958), Henn et al. (2001), Paz-Ferreiro et al. (2013)]. Accordingly, in the particular case of smectite-rich materials, high CEC and high electrical conductivity cannot be explained solely by a high external SSA. The interfoliar spaces (internal SSA) significantly contribute to cations transfer, which is taken into account in the phenomenological model presented here.

A behaviour of similar nature occurs for Li-ion transport in batteries, with smectite sheets being an analog to cobalt-oxide sheets (Howard et al. 2010). In both cases, the removal of positive charge from the interlayer space is compensated; in our case by the constant supply of cations from surrounding smectite sheets and in the case of Li-ion batteries by the loss of electrons during cobalt oxidation.

\subsection{Electrical conduction in other alteration minerals}

We have assumed in this study that there were only two types of contributors to conductivity: the pore fluid and smectite sheets. However, altered igneous rocks contain other minerals, which are susceptible to conduct the electrical current. We briefly discuss here the possible contributions of zeolites and pyrite.

This study does not show a clear contribution of zeolites to electrical conductivity, which is consistent with other studies, e.g. with electrical logs in hole 504B of the Ocean Drilling Project (Pezard 1990) and with laboratory results of Revil et al. (2002). Zeolites such as heulandite have a high CEC, as opposed to wairakite and laumontite (Table 1), although it is not accounted for in the CEC measured by 


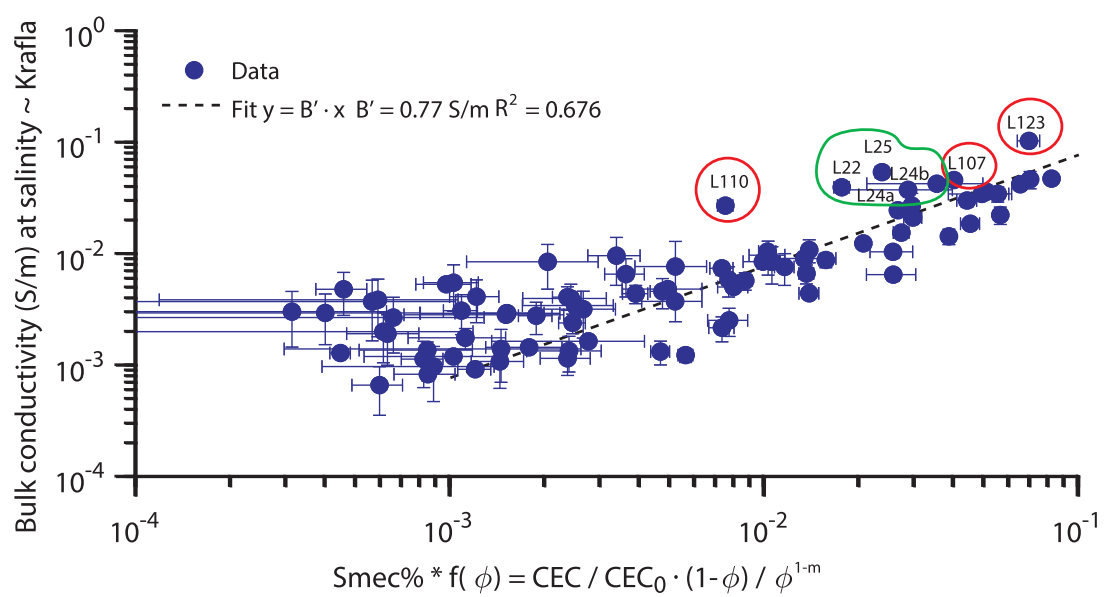

Figure 10. Simplified analysis using minimum number of parameters: conductivity at low fluid conductivity (average of two measurements between 0.03 and $0.1 \mathrm{~S} \mathrm{~m}^{-1}$ ), CEC and porosity. Two groups of outliers are indicated: samples circled in green contain a significant amount of pyrite (9-14 wt. per cent), which may affect the electrical conductivity, while samples circled in red contain little to no sulphide or iron oxide but may contain very connected smectite particles.

Cu-trien, as explained in Section 4.1. As a consequence, heulandite-type zeolites may have high intrinsic conductivity. However, heulandite tends to form large crystals and precipitate in bulk rather than in a continuous fashion, as opposed to smectite. This may explain why a contribution of heulandite to electrical conduction is not clearly seen, but electrical measurements on pure heulandite are necessary to advance further this question.

Sample L25 deviates from the trend of Fig. 7. This can be explained by the presence of veined pyrite, which could be sufficiently connected to provide another conduction path [see e.g. Thommerel et al. (2002)]. It is also common to observe electrical polarization associated to the presence of pyrite (Wong 1979). Polarization is observed in samples containing a significant amount of pyrite (see Fig. 3 for sample L22) but the effect on the in-phase conductivity at $1 \mathrm{kHz}$ is limited to less than 2 per cent of the total value (see Section 3.5.1.).

\subsection{Upscaling laboratory results to geophysical interpretation}

In this section, we address several obstacles, which need to be overcome before laboratory results can be exploited for geophysical applications, and in particular for geothermal exploration. First, we investigate to what extent the expression of bulk electrical conductivity can be simplified in order to calculate porosity and smectite content from field electrical measurements. Then, we show the limits of interpreting the mineralogy in terms of reservoir temperature. Finally, we compare the electrical resistivity values obtained in laboratory to resistivity values obtained by borehole logging in two of the boreholes.

Since electrical measurements in the field are made at the in situ fluid conductivity, it is impossible to use directly the functions presented in Sections 4.2 and 4.3. For fluid conductivities lower than $0.1 \mathrm{~S} \mathrm{~m}^{-1}$ (typical of the Krafla geothermal system), the term $\sigma_{E D L}$ in eq. (13) may represent the largest part of the bulk conductivity (see e.g. Fig. 9b). Based on the semi-quantitative relationship between the parameter $c$ and $Q_{\mathrm{v}} / F$ suggested by Waxman \& Smits (1968) and shown in Fig. C2, eq. (16) presents a simplified function of smectite content and porosity describing the bulk conductivity, under the assumption that $\sigma_{\mathrm{EDL}} \gg \frac{\sigma_{\mathrm{W}}}{F}$ and $\sigma_{\mathrm{EDL}} \gg \sigma_{\text {intra-solid }}$.

$$
\begin{aligned}
\sigma_{\text {bulk for } \sigma_{\mathrm{w}}=0.03-0.1 \mathrm{Sm}^{-1}} & \approx \sigma_{\mathrm{EDL}} \approx B^{\prime} \cdot \frac{\mathrm{CEC}}{\mathrm{CEC}_{0}} \cdot \frac{1-\phi}{F \phi} \\
& \approx B^{\prime} \cdot \operatorname{Smec} \% \cdot \frac{1-\phi}{\phi^{1-m}},
\end{aligned}
$$

We have three constants: $\mathrm{CEC}_{0}=91 \pm 8 \mathrm{meq} / 100 \mathrm{~g}=88 \pm 8 \mathrm{C} \cdot \mathrm{g}^{-1}$ is the average CEC of pure smectite (Fig. 4 ); $m=2.3$ is the exponent of Archie's approximation $F=\phi^{-\mathrm{m}}$ (Fig. C1) and $B^{\prime}=(7.7 \pm 0.7) \cdot 10^{-1} \mathrm{~S} \cdot \mathrm{m}^{-1}$ is a proportionality constant (Fig. 10).

Eq. (16) can predict, to some extent, the electrical conductivity measured in Krafla (Fig. 10). Although eq. (16) cannot separate the effects of porosity and smectite content based on a single conductivity measurement, it can provide relevant information about porosity and formation factor in drill holes where electrical logs are measured and drill cuttings available for CEC measurements. Moreover, a general consistency between the quantity of alteration (using XRD quantification of the mineralogy) and porosity is observed for all samples (Fig. 11), indicating that porosity and smectite content (one of the first alteration products) are not independent parameters. A possible explanation for this consistency is the lithological control on both the porosity and alteration quantity: while hyaloclastite are very porous and glassy (thus easily altered), intrusions have very low porosity and higher crystallinity (thus harder to alter).

However, two groups of outliers are evident in Fig. 10, showing the limits of this simplified function. The samples circled in green contain 9-14wt. per cent pyrite, which is ignored in eq. (16). Electronic conduction throughout pyrite grains could be included in the term $\sigma_{\text {intra-solid }}$ if a contact between electronic and ionic conductions can be ensured at the pyrite/water interface. The samples circled in red contain little to no sulphide or iron oxide. The higher conductivity observed in these samples, compared to the general trend, can be explained by 


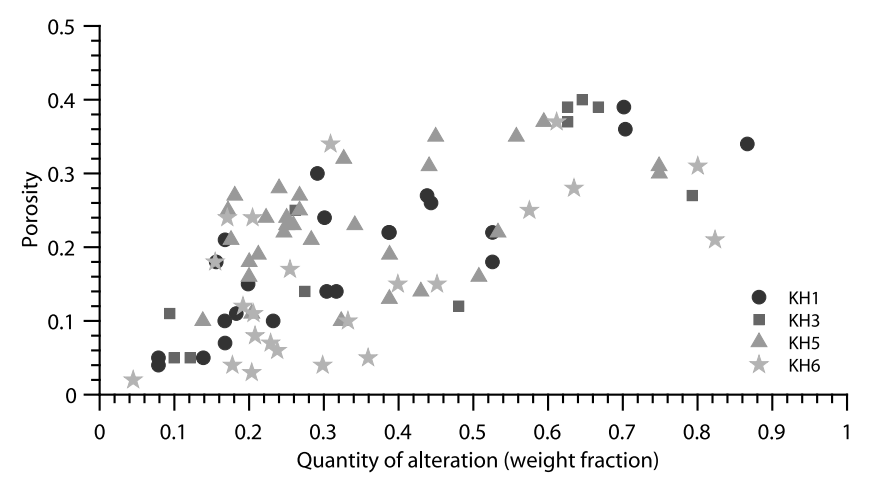

Figure 11. Comparison between quantity of alteration and porosity for all samples. The following minerals, quantified by Rietveld refinements of XRD patterns, were accounted for in the alteration: smectite, zeolites, chlorite, wairakite, epidote, amphibole, prehnite, pyrite, titanite and Fe-Ti oxides.

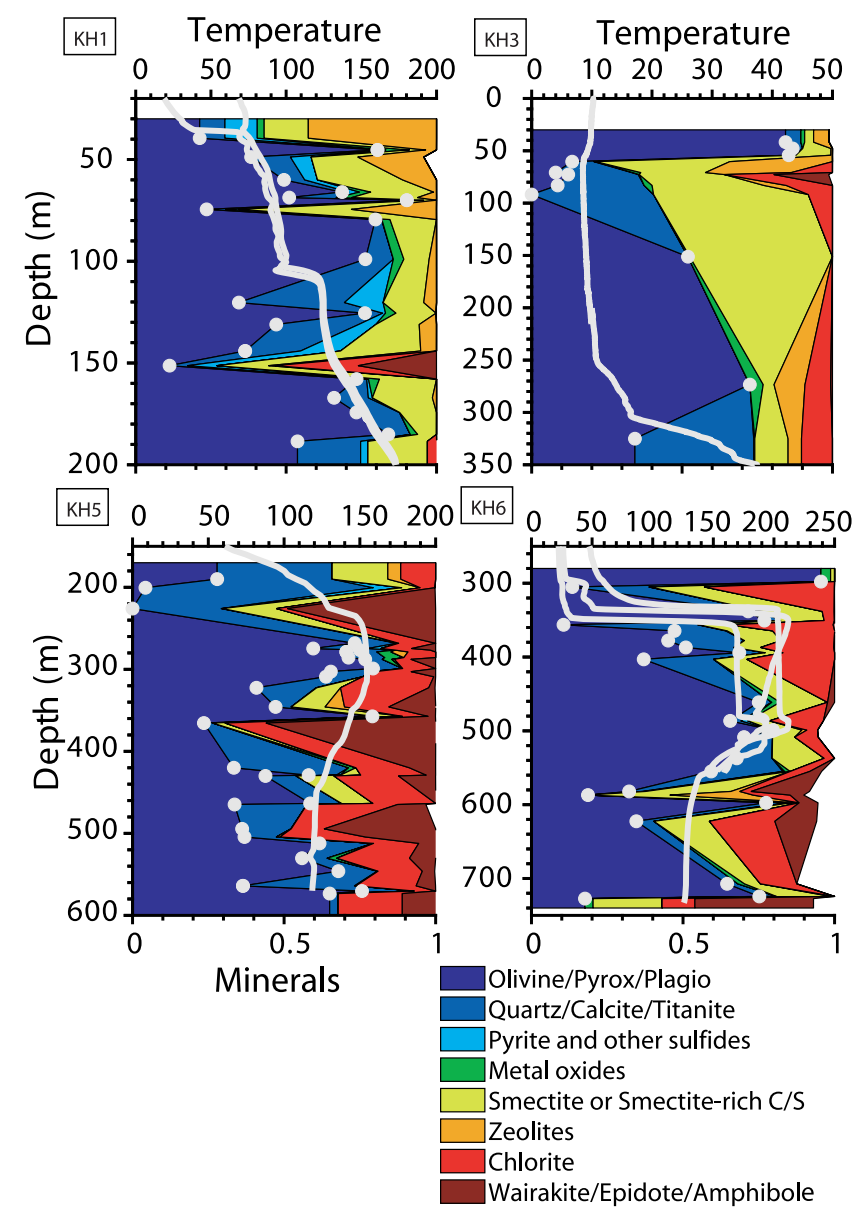

Figure 12. Comparison between mineralogy (quantified by Rietveld refinements of XRD analyses on powders) and temperature (borehole logging, white thick line) in (a) KH1, (b) KH3, (c) KH5 and (d) KH6. The filled white circles only give the depth of each analysed sample.

more connectivity of smectite particles, which is also a parameter ignored in eq. (16). A high connectivity indicates that smectite particles are rather distributed in a fracture network [see Fig. 9(d)] than isolated in voids, which is valuable information for geothermal exploration. Next steps to gain a better understanding of these effects would be to measure independently the connectivity of smectite particles and to study the conduction processes associated to the presence of veined pyrite. Finally, in the range $0.03-0.1 \mathrm{~S} \mathrm{~m}^{-1}$ used here, the term $\sigma_{\text {intra-solid }}$ increases rapidly with fluid conductivity for samples with high smectite content (eq. 15). In these conditions, electrical conductivity may also be sensitive to slight variations of fluid composition.

The boundary between smectite and chlorite is often used as a geotherm (see e.g. Kristmannsdóttir 1979) because thermodynamics predicts two distinct stability domains for chlorite and smectite, controlled by the temperature and at a smaller scale, the fluid/mineral chemistry (Vidal et al. 2012). In diagenetic smectite-chlorite series, discrete smectite is indeed found in the range of temperature predicted by thermodynamics, i.e. $80-180^{\circ} \mathrm{C}$, while chlorite dominates at higher temperatures (Beaufort et al. 2015). However, in active volcanic systems 

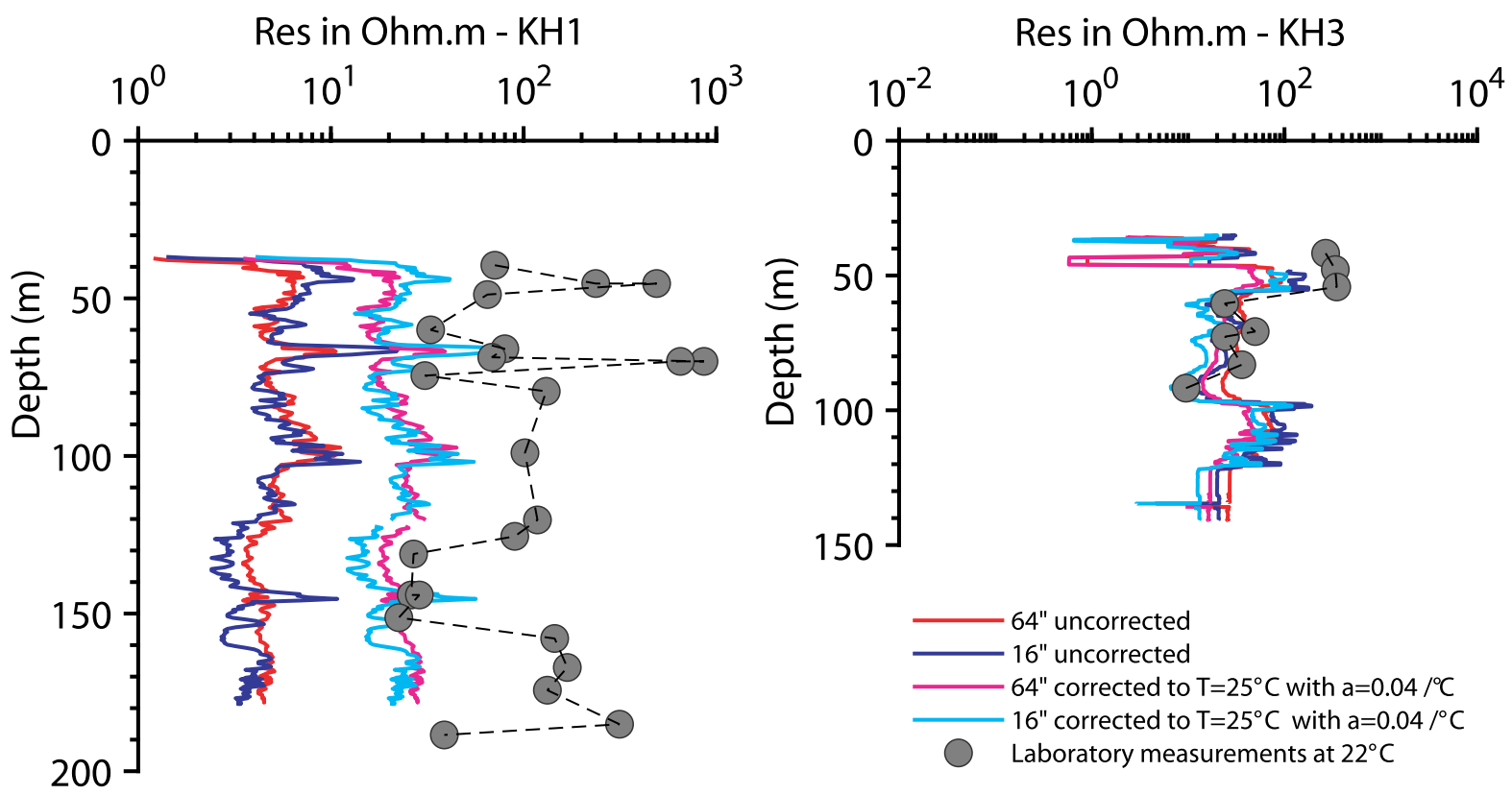

Figure 13. Comparison of resistivity data obtained in the lab with resistivity logs at two boreholes (KH1 and KH3). The raw data from the 16/64 logging tool are in dark blue and red, while the corrected data, accounting approximately for the effect of temperature difference are in light blue and pink. The grey circles are laboratory measurements, and the black hatched lines are only guiding the eye: the resistivity is probably not so straight between samples.

such as Chipilapa (El Salvador) and Milos (Greece), smectite is observed at temperature higher than $300^{\circ} \mathrm{C}$ by Beaufort et al. (1995), while in Icelandic volcanic systems, discrete chlorite only appears above $270{ }^{\circ} \mathrm{C}$ (Schiffman \& Fridleifsson 1991). These studies therefore indicate that care must be taken when inferring absolute temperature values.

Our set of samples confirms some discrepancy between theoretical equilibrium temperature based on mineral assemblages and actual temperature measured in situ. The temperature profiles of the four boreholes are presented in Fig. 12. The temperature in KH3 is low: mainly $10{ }^{\circ} \mathrm{C}$ and increasing to $40{ }^{\circ} \mathrm{C}$ at the bottom, while the temperature in $\mathrm{KH} 6$ is high: $220^{\circ} \mathrm{C}$ at $500 \mathrm{~m}$ depth. The temperatures in $\mathrm{KH} 1$ and KH5 are intermediate. The distribution of minerals in these boreholes (as quantified by XRD on each sample), also shown in Fig. 12, is different from what would be expected if the system was at an equilibrium. In $\mathrm{KH} 6$, smectite is found at temperatures up to $220^{\circ} \mathrm{C}$. In $\mathrm{KH} 5$, 'high-temperature' alteration minerals (epidote, actinolite, wairakite) are found in horizons where the temperature does not exceed $150{ }^{\circ} \mathrm{C}$. In $\mathrm{KH} 3$, large amounts of chlorite are found in horizons where the temperature does not exceed $10^{\circ} \mathrm{C}$ : chlorite was most likely formed at an earlier stage, when the temperature was superior to $200^{\circ} \mathrm{C}$. In KH1, wairakite and chlorite are found in large amount in sample L25, whereas the two neighboring samples with similar temperature (L24-7m above and L26-6m below) do not contain any of these minerals. The distribution of minerals can, therefore, not be directly interpreted in terms of the present temperature of the system.

Resistivity values from borehole logs (using a 16/64 tool: measurements made with 16 and 64 inches spacing between electrodes) and from laboratory experiments on cores are compared on Fig. 13 for boreholes $\mathrm{KH} 1$ and $\mathrm{KH} 3$. The laboratory measurements were performed at $22{ }^{\circ} \mathrm{C}$ and the fluid conductivity used for the comparison is in the range $0.03-0.07 \mathrm{~S} \mathrm{~m}^{-1}$. No borehole logs were available in KH5 and KH6.

A correction is made to account for the effects of the temperature in the borehole measurements, using the temperature presented in Fig. 12 and eq. (17).

$\frac{\sigma(T)}{\sigma\left(T_{0}\right)}=1+\alpha_{T_{0}}\left(T-T_{0}\right)$,

where $T$ and $T_{0}$ are the actual and reference temperature, respectively, and $\alpha_{T_{0}}$ is the correction coefficient, which varies with the reference temperature $T_{0}$ and the type of medium conducting the electrical current. The two coefficients $\alpha_{T_{0} \text {,fluid }}=0.023{ }^{\circ} \mathrm{C}^{-1}$ and $\alpha_{T_{0} \text {,clay }}=0.04{ }^{\circ} \mathrm{C}^{-1}$, used by Kulenkampff et al. (2005), based on calculations by Revil et al. (1998) for $T_{0}=25^{\circ} \mathrm{C}$, are tested here. The largest corrections, using $\alpha_{T_{0}, \text { clay }}$, are presented in Fig. 13.

Corrections in $\mathrm{KH} 3$ are small and laboratory data are consistent with borehole data. In KH1 the correction of the borehole data has an important effect. Although the correction is overestimated in Fig. 13, the corrected resistivity logs do not reach the higher resistivity values found in laboratory data. Most of the relative variations are well preserved (at 50, 70 and $140 \mathrm{~m}$ ), despite a slight depth shift. The relative variations of the laboratory resistivity are larger (higher peaks and lower lows) than those of the borehole logs. This can be explained by the averaging inherent to the logging tool, while core measurements are made more locally. The difference of an order of magnitude between the baselines of laboratory and borehole resistivity, especially at deeper levels, needs to be investigated. A systematic bias in the measurement by the 16/64 tool, for example due to conductive lead in the tool, may be a cause for this shift. 


\subsection{How can these results be useful for geothermal exploration?}

Although alteration minerals should not be used directly as a temperature index, the presence of smectite (outside the shallow 'clay cap', where smectite is thermodynamically stable), especially connected smectite, gives valuable information about the status of the system such as boiling, recent fault opening or chemical disequilibrium. Indeed Beaufort et al. (1995) show a strong correlation between the presence of smectite and horizons with highly active hydrothermal circulations. This correlation was also confirmed by Patrier et al. (1996). In borehole KH6 at Krafla, a strong temperature gradient is observed at $350 \mathrm{~m}$. An intense circulation of hydrothermal fluids at this depth is likely and could have caused the formation of connected smectite in a fracture network. This would explain the high conductivity in sample L110 (depth: $356 \mathrm{~m}$ ), the most striking outlier in Fig. 10. Detecting the presence of connected smectite with electrical soundings is, therefore, interesting for understanding the dynamics of hydrothermal systems.

\section{CONCLUSIONS}

We show that:

(1) CEC measurements using Cu-trien provide a reliable measure of the weight fraction of smectite sheets in altered volcanic samples containing up to 15 different minerals, including zeolites, chlorite and corrensite. Our results extend the result of Kaufhold \& Dohrmann (2003), who suggested that CEC using Cu-trien is proportional to smectite content in bentonites.

(2) Samples containing a high amount of smectite sheets show an important deviation from a linear relationship between bulk conductivity and pore fluid conductivity. A power function with three free parameters is suggested here. It approaches a linear relationship when the amount of smectite is low. A new parameter $b$, used as an exponent to the fluid conductivity, is close to 1 for samples where the ratio between smectite sheets and volume of fluid is less than 25 per cent and decreases for samples with higher ratio.

(3) This non-linear behaviour is interpreted to originate from a conduction pathway in addition to pathways involving pore fluid and crystal edges (EDL). A conceptual model is suggested: cations cross the solid lattice through connected interfoliar spaces of smectite sheets. A new model, corresponding to the sum of the three pathways in parallel, fits the whole dataset.

(4) The bulk conductivity at low fluid conductivity can be semi-quantitatively approximated by a function of porosity and smectite quantity, in the absence of highly connected smectite and/or pyrite. However, small variations in fluid conductivity can significantly affect the bulk conductivity if a large amount of smectite is present.

This study provides improved understanding of electrical conduction in smectite-rich rocks: electrical conduction through interfoliar spaces of smectite sheets is a physical process that can explain our observations. Further measurements can provide more details on this process, and its importance and relevance amongst other conduction processes.

\section{ACKNOWLEDGEMENTS}

LL warmly thanks Sigurður Sveinn Jónsson, Helga Margrét Helgadóttir and Bjarni Gautason for their help with identifying primary and alteration minerals and Dráinn Friðriksson for his help in understanding the thermodynamics of cation exchanges and his explanations about zeolites. Christophe Nevado, Doriane Delmas and Khaled Oubellouch are thanked for the preparation of thin sections. LL is very thankful to Bruno Lanson and Nathanaël Findling, whose help with XRD quantification of mineralogy has been invaluable. LL also thanks Alain Meunier, Eric Ferrage Emmanuel Tertre, Daniel Beaufort, Patricia Patrier and Philippe Cosenza for sharing their eclectic knowledge about cation exchanges and expandable minerals. André Revil is thanked for his explanations about the current theory of electrical conduction in rocks, as well as for suggesting the use of a four-electrode set-up for electrical measurements. Thanks also to Yves Guéguen, Jérôme Fortin and Aurélien Nicolas for their explanations about non-linear phenomena in rock physics. Nicolas Marino is thanked for his assistance in electrical conductivity measurements and Christina Guenther and Ester Inga Ingólfsdóttir for their valuable help with CEC measurements. Thanks to Nataliya Denchik and Knútur Árnason for their help in interpreting borehole resistivity logs. Finally, the authors are grateful to Landsvirkjun, and especially Ásgrímur Guðmundsson, for providing the data and cores for this work. This research was supported by the IMAGE FP7 EC project (Integrated Methods for Advanced Geothermal Exploration, grant agreement no. 608553) and by a PhD grant from Paris Sciences et Lettres. The two anonymous reviewers are sincerely thanked for their constructive comments and interesting ideas.

\section{REFERENCES}

Alt, J.C., Honnorez, J., Laverne, C. \& Emmermann, R., 1986. Hydrothermal alteration of a $1 \mathrm{~km}$ section through the upper oceanic crust, Deep Sea Drilling Project Hole 504B: mineralogy, chemistry and evolution of seawater-basalt interactions, J. geophys. Res., 91, 10309-10335.

Ames, L.L., 1966. Cation exchange properties of wairakite and analcime, Am. Mineral., 51, 39-42.

Archie, G.E., 1942. The electrical resistivity log as an aid in determining some reservoir characteristics, Trans. AIME, 146, 54-62.
Árnason, K., Eysteinsson, H. \& Hersir, G.P., 2010. Joint 1D inversion of TEM and MT data and 3D inversion of MT data in the Hengill area, SW Iceland, Geothermics, 39, 13-34.

Árnason, K., Karlsdóttir, R., Eysteinsson, H., Flóvenz, Ó.G. \& Gudlaugsson, S.T., 2000. The resistivity structure of high-temperature geothermal systems in Iceland, in World Geothermal Congress, pp. 923-928, KyushuTohoku, Japan.

Beaufort, D., Papapanagiotou, P., Patrier, P., Fujimoto, K. \& Kasai, K., 1995. High-temperature smectites in active geothermal systems, Proceedings 
8th Water-Rock Interaction Symposium, Vladivostok, in Water-Rock Interaction, edsKharaka \&Chudaev. Balkema, Rotterdam, pp. 493-496.

Beaufort, D., Rigault, C., Billon, S., Billault, V., Inoue, A., Inoue, S. \& Patrier, P., 2015. Chlorite and chloritization processes through mixed-layer mineral series in low-temperature geological systems - a review, Clay Miner., 50, 497-523.

Bish, D.L. \& Reynolds, R.C., 1989. Sample preparation for X-ray diffraction, Rev. Mineral. Geochem., 20, 73-99.

Bouchet, A., Meunier, A. \& Sardini, P., 2000. Minéraux Argileux: Structure Cristalline, Identification Par Diffraction de Rayons X, edn, Vol. 23, Editions Elf Exploration.

Chester, F.M. et al., 2013. Structure and composition of the Plate-Boundary slip zone for the 2011 Tohoku-Oki Earthquake, Science, 342, 1208

Diamond, S. \& Kinter, E.B., 1958. Surface areas of clay minerals as derived from measurements of glycerol retention, Clays Clay Miner., 5, 334-347.

Douglas, G.R., 1981. The development of bonded discontinuities in basalt, and their significance to freeface weathering, Jökull, 31, 1-9.

Dyer, A.S., 1991. The natural zeolite, laumontite, as a potential material for the treatment of aqueous nuclear waste, J. Radioanal. Nucl. Chem., Lett., 154, 265-276.

Ferrage, E., 2016. Investigation of the interlayer organization of water and ions in smectite from the combined use of diffraction experiments and molecular simulations. A review of methodology, applications, and perspectives, Clays Clay Miner., 64, 348-373.

Ferrage, E., Lanson, B., Sakharov, B.A. \& Drits, V.A., 2005. Investigation of smectite hydration properties by modeling experimental X-ray diffraction patterns: Part I. Montmorillonite hydration properties, Am. Mineral., 90, $1358-1374$

Flóvenz, Ó.G., Georgsson, L.S. \& Árnason, K., 1985. Resistivity structure of the upper crust in Iceland, J. geophys. Res., 90, 10136-10150.

Flóvenz, Ó.G., Hersir, G.P., Sæmundsson, K., Ármannsson, H. \& Friðriksson, T., 2012. Geothermal energy exploration techniques, ed. Sayigh, A., 7, 51-95, Oxford: Elsevier.

Flóvenz, Ó.G., Spangenberg, E., Kulenkampf, J., Arnason, K., Karlsdottir, R. \& Huenges, E., 2005. The role of electrical interface conduction in geothermal exploration, in Proceedings of the 2005 World Geothermal Congress, Ankara, Turkey, Paper 0742, 9.

Fridriksson, T., Neuhoff, P.S., Vinani, B.E. \& Bird, D.K., 2004. Experimental determination of thermodynamic properties of ion-exchange in heulandite: binary ion-exchange experiments at 55 and $85^{\circ} \mathrm{c}$ involving $\mathrm{Ca} 2+$, $\mathrm{Sr} 2+, \mathrm{Na}+$ and $\mathrm{K}+$, Am. J. Sci., 304, 287-332.

Gautason, B., Egilson, T., Anett, B. \& Danielsen, P.E., 2007. Krafla: Borun Tveggja Kjarnahola, KH5 og KH6, Veturinn 2006-2007, ÍSOR, Reykjavik, Iceland.

Glover, P.W.J., 2016. Archie's law - a reappraisal, Solid Earth, 7, 1157-1169.

Guðmundsson, Á., 1991. Borun Kjarnaholu i Sandabotnaskarði, Orkustofnun, Reykjavik, Iceland.

Gudmundsson, B.T. \& Arnórsson, S., 2002. Geochemical monitoring of the Krafla and Námafjall geothermal areas, N-Iceland, Geothermics, 31(2), 195-243.

Gueguen, Y. \& Dienes, J., 1989. Transport properties of rocks from statistics and percolation, Math. Geol., 21, 1-13.

Henn, F., Durand, C., Cerepi, A., Brosse, E. \& Giuntini, J.C., 2001. Are pore lining chlorites a cause of low resistivity in sandstones? Soc. Core Anal., 34, $1-12$.

Hersir, G.P. \& Björnsson, A., 1991. Geophysical Exploration for Geothermal Resources: Principles and Application, Orkustofnun, Reykjavik, Iceland.

Hill, H.J. \& Milburn, J.D., 1956. Effect of clay and water salinity on electrochemical behavior of reservoir rocks, Soc. Petrol. Eng, 207, 65-72.

Howard, W.G., Schmidt, C.L. \& Scott, E.R., 2010. Lithium-Ion Battery Google Patents, U.S. Patent number 7,662,509, 16. Feb. 2010.

Hower, J. \& Mowatt, T.C., 1966. The mineralogy of illites and mixed-layer illite/montmorillonites, Am. Mineral., 51, 825-854.

Hyndman, R.D., Yamano, M. \& Oleskevich, D.A., 1997. The seismogenic zone of subduction thrust faults, Island Arc, 6, 244-260.

Jónsson, S.S., Guðmundsson, A. \& Thordarson, S., 2003. Krafla: Borun Kjarnaholu KH3 Milli Jörundar og Háganga, ÍSOR, Reykjavik, Iceland.
Kaufhold, S. \& Dohrmann, R., 2003. Beyond the methylene blue method: determination of the smectite content using the cutriene method, Z. Angew. Geol., 49, 13-17.

Kristinsdóttir, L.H., Flóvenz, Ó.G., Árnason, K., Bruhn, D., Milsch, H., Spangenberg, E. \& Kulenkampff, J., 2010. Electrical conductivity and Pwave velocity in rock samples from high-temperature Icelandic geothermal fields, Geothermics, 39, 94-105.

Kristmannsdóttir, H., 1975. Clay minerals formed by hydrothermal alteration of basaltic rocks in Icelandic geothermal fields, GFF, 97, 289-292.

Kristmannsdóttir, H., 1979. Alteration of Basaltic Rocks by HydrothermalActivity at $100-300^{\circ}$ C, Dev. Sedimentol., 27, 359-367.

Kulenkampff, J., Spangenberg, E., Flóvenz, Ó.G., Raab, S. \& Huenges, E., 2005. Petrophysical parameters of rocks saturated with liquid water at high temperature geothermal reservoir conditions, in World Geothermal Congress, pp. 24-29, Antalya, Turkey.

Lagaly, G., 1981. Characterization of clays by organic compounds, Clay Miner., 16, 1, 1-21.

Leroy, P. \& Revil, A., 2009. A mechanistic model for the spectral induced polarization of clay minerals, J. geophys. Res., 114.

Lévy, L., Flóvenz, Ó.G. \& Hersir, G.P., 2016. Quantitative Impact of Hydrothermal Alteration on Electrical Resistivity, Based on Cores from Krafla, in IMAGE Task 3.3 - Physical properties of rock at reservoir conditions, Iceland GeoSurvey (ISOR).

Lyklema, J., 2001. Fundamentals of Interface and Colloid Science. Volume II Solid-Liquid Interfaces, Academic Press.

Meier, L. \& Kahr, G., 1999. Determination of the cation exchange capacity (CEC) of clay minerals using the complexes of Copper(II) ion with Triethylenetetramine and Tetraethylenepentamine, Clays Clay Miner, 47, 386-388.

Meunier, A., 2005. Clays, Springer.

Patrier, P., Papapanagiotou, P., Beaufort, D., Traineau, H., Bril, H. \& Rojas, J., 1996. Role of permeability versus temperature in the distribution of the fine $(<0.2 \mu \mathrm{m})$ clay fraction in the Chipilapa geothermal system (E1 Salvador, Central America), J. Volc. Geotherm. Res., 72, 101-120.

Paz-Ferreiro, J., da Luz, L.R.Q.P., Lado, M. \& Vázquez, E.V., 2013. Specific surface area and multifractal parameters of associated nitrogen adsorption and desorption isotherms in soils from Santa Catarina, Brazil, Vadose Zone J., 12.

Pezard, P.A., 1990. Electrical properties of mid-ocean ridge basalt and implications for the structure of the upper oceanic crust in Hole 504B, $J$. geophys. Res., 95, 9237-9264.

Revil, A., Cathles, L.M., Losh, S. \& Nunn, J.A., 1998. Electrical conductivity in shaly sands with geophysical applications, J. geophys. Res., 103, 23925-23936.

Revil, A., Hermitte, D., Spangenberg, E. \& Cochemé, J.J., 2002. Electrical properties of zeolitized volcaniclastic material, J. geophys. Res., 107.

Revil, A., Le Breton, M., Niu, Q., Wallin, E., Haskins, E. \& Thomas, D.M., 2017 a. Induced polarization of volcanic rocks - 1 . Surface versus quadrature conductivity, Geophys. J. Int., 208, 826-844.

Revil, A., Murugesu, M., Prasad, M. \& Le Breton, M., 2017b. Alteration of volcanic rocks: a new non-intrusive indicator based on induced polarization measurements, J. Volc. Geotherm. Res., 341, 351-362.

Richman, D. \& Thomas, H.C., 1956. Self-diffusion of sodium in a cation exchange resin, J. Phys. Chem., 60, 237-239.

Rink, M. \& Schopper, J.R., 1974. Interface conductivity and its implications to electric logging, in SPWLA 15th Annual Logging Symposium, ,Analysts, S. o. P. a. W.-L, Society of Petrophysicists and Well-Log Analysts,

Schiffman, P. \& Fridleifsson, G.O., 1991. The smectite-chlorite transition in drillhole N 1-15, Nesjavellir geothermal field, Iceland: XRD, BSE and electron microprobe investigations, J. Metamorph. Geol., 9, 679-696.

Sigmundsson, F., 2006. Iceland Geodynamics: Crustal Deformation and Divergent Plate Tectonics, Springer Science \& Business Media.

Taut, T., Kleeberg, R. \& Bergmann, J., 1998. Seifert Software: the new Seifert Rietveld program BGMN and its application to quantitative phase analysis, Mater. Struct., 5, 57-66.

Thommerel, E., Valmalette, J.C., Musso, J., Villain, S., Gavarri, J.R. \& Spada, D., 2002. Relations between microstructure, electrical percolation 
and corrosion in metal-insulator composites, Mater. Sci. Eng. A, 328, $67-79$.

Vidal, O., Baldeyrou, A., Beaufort, D., Fritz, B., Geoffroy, N. \& Lanson, B., 2012. Experimental study of the stability and phase relations of clays at high temperature in a thermal gradient, Clays Clay Miner., 60, 200-225.

Vinegar, H.J. \& Waxman, M.H., 1984. Induced polarization of shaly sands, Geophysics, 49, 1267-1287.

Vogt, K. \& Köster, H.M., 1978. Zur mineralogie, kristallchemie und geochemie einiger montmorillonite aus bentoniten, Clay Miner., 13, 25-43.

Walker, G.P.L., 1960. Zeolite zones and dike distribution in relation to the structure of the basalts of eastern Iceland, J. Geol., 68, 515-528.
Waxman, M.H. \& Smits, L.J.M., 1968. Electrical conductivities in oilbearing shaly sands, Soc. Pet. Eng. J., 8, 107-122.

Waxman, M.H. \& Thomas, E.C., 1974. Electrical conductivities in Shaly Sands-I. The relation between hydrocarbon saturation and resistivity index; II. The temperature coefficient of electrical conductivity, J. Petrol. Tech., 26, 213-225.

Winsauer, W.O., Shearin, H.M., Jr, Masson, P.H. \& Williams, M., 1952. Resistivity of brine-saturated sands in relation to pore geometry, $A A P G$ Bull., 36, 253-277.

Wong, J., 1979. An electrochemical model of the induced-polarization phenomenon in disseminated sulfide ores, Geophysics, 44, 1245-1265.

\section{SUPPORTING INFORMATION}

Supporting information are available at $G J I$ online.

SupplementaryTable_2elec.pdf

SupplementaryTable_4elec.pdf

Please note: Oxford University Press are not responsible for the content or functionality of any supporting materials supplied by the authors.

Any queries (other than missing material) should be directed to the corresponding author for the paper.

\section{APPENDIX A: ELECTRICAL IMPEDANCE MEASUREMENTS}

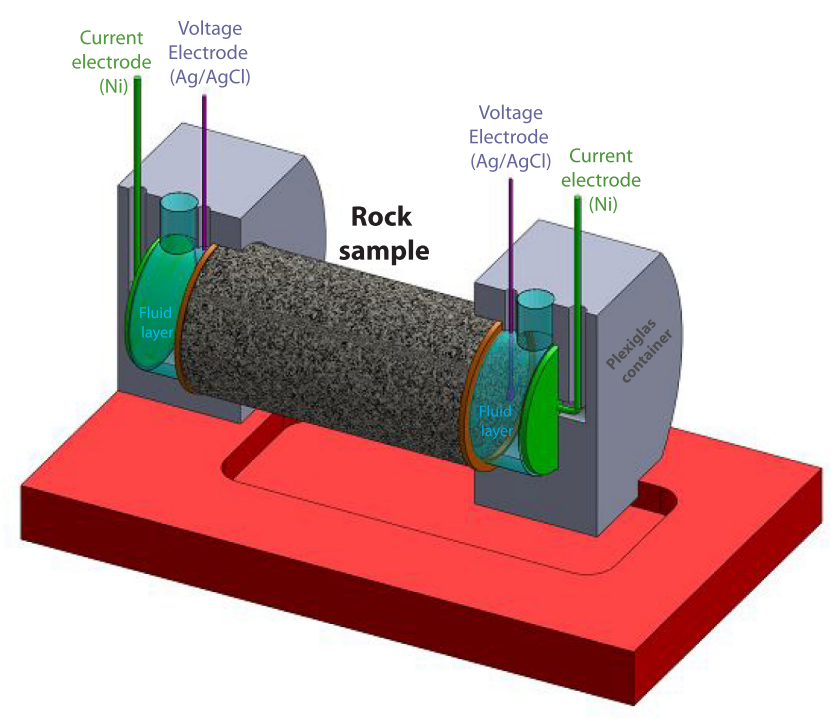

Figure A1. Schematic view of the four-electrode measurement cell. The spaces between current and voltage electrodes are filled with water at the same fluid conductivity as the fluid saturating the sample. This water layer ensures the contact between the injected current and the sample. 

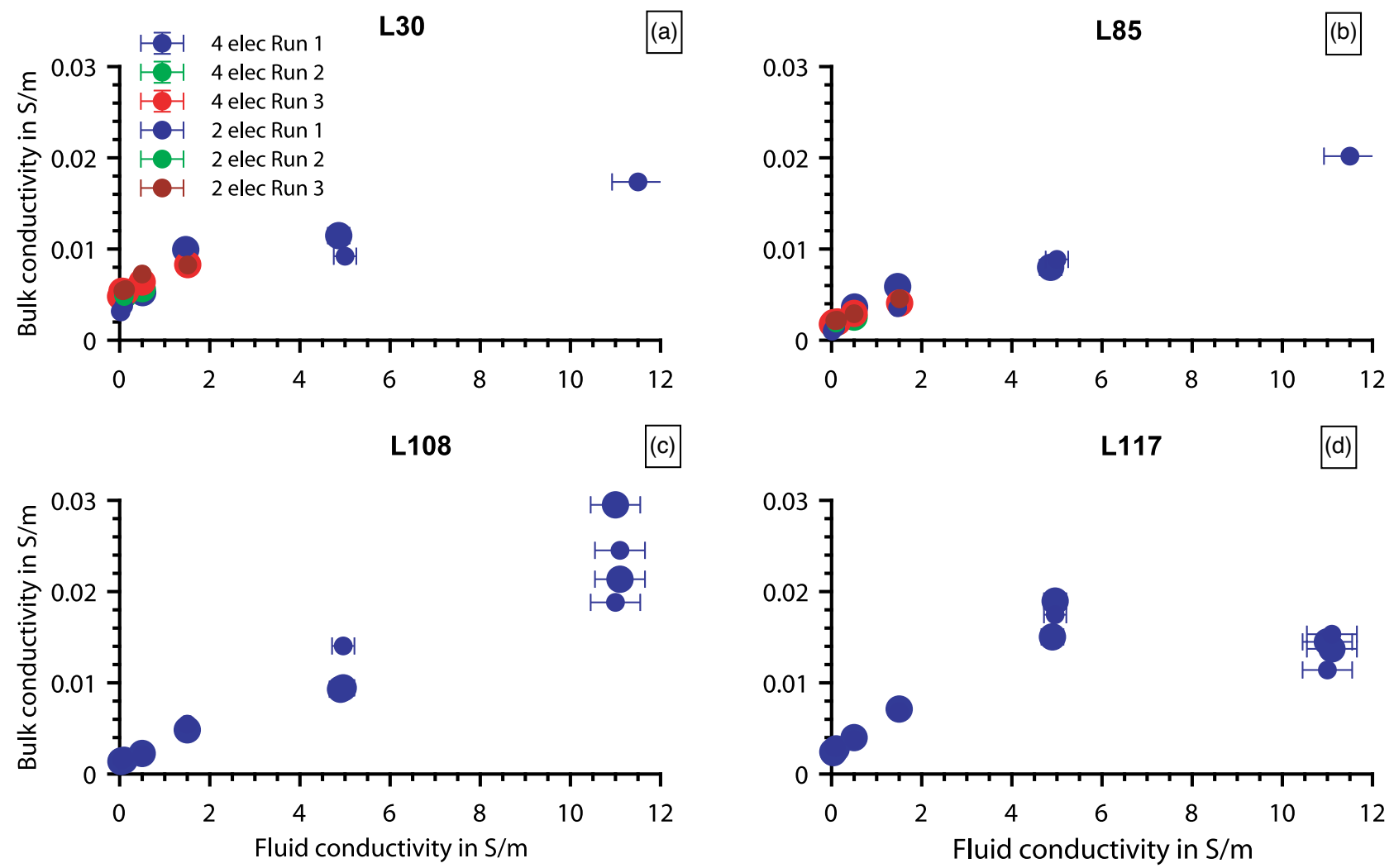

Figure A2. Four samples with unreliable electrical data (L30, L85, L108 and L117). Fitting the variations with fluid conductivity is not possible. The same applies for eight other samples: L12a, L35, L76, L81, L104, L106, L111 and L112.

APPENDIX B: PETROPHYSICS AND MINERALOGY DATA 
Table B1. Key parameters for samples: CEC, along with its uncertainty $(\mathrm{Unc} \mathrm{CEC})$, porosity, $Q_{\mathrm{v}}$ and mineralogy distribution. Poro $=$ porosity; Plg $=$ plagioclases; $\mathrm{Ol}=$ olivine; $\mathrm{Pyx}=$ pyroxènes; $\mathrm{Smec}=$ Smectite (also includes corrensite or smectite-rich mixed-layer clay in samples where chlorite is present); $\mathrm{Chl}=$ chlorite (can include chlorite-rich mixed-layer clay); Zeol = zeolites (includes: heulandites, laumontite and other zeolites); Wai $=$ wairakite; Amp = amphiboles; ep = epidote; Pre = prehnite; Pyr = pyrite (includes other sulphides); Fe-ox = iron oxides (includes titano-magnetite, ilmenite and hematite); Tit $=$ titanite; $\mathrm{Qtz}=$ quartz; $\mathrm{Clc}=$ calcite.

\begin{tabular}{|c|c|c|c|c|c|c|c|c|c|c|c|c|c|c|c|}
\hline ID & CEC & $\begin{array}{l}\text { Unc } \\
\text { CEC }\end{array}$ & Poro & $\begin{array}{c}\text { Grain } \\
\text { density }\end{array}$ & $Q \mathrm{v}$ & $\begin{array}{c}\mathrm{Plg} \& \mathrm{Ol} \\
\& \mathrm{Pyx}\end{array}$ & $\begin{array}{l}\text { Smec or } \\
\text { MLC }\end{array}$ & $\mathrm{Chl}$ & Zeol & Wai & $\begin{array}{c}\text { Amp \& } \\
\text { Ep \& Pre }\end{array}$ & Pyr & Fe-ox & Tit & $\begin{array}{c}\text { Qtz \& } \\
\text { Clc }\end{array}$ \\
\hline Unit & $\mathrm{Cg}^{-1}$ & $\mathrm{Cg}^{-1}$ & $\begin{array}{l}\text { per } \\
\text { cent }\end{array}$ & $\mathrm{g} \mathrm{cm}^{-3}$ & $\begin{array}{c}\mathrm{C} \\
\mathrm{cm}^{-3}\end{array}$ & per cent & per cent & $\begin{array}{l}\text { per } \\
\text { cent }\end{array}$ & $\begin{array}{l}\text { per } \\
\text { cent }\end{array}$ & $\begin{array}{l}\text { per } \\
\text { cent }\end{array}$ & per cent & $\begin{array}{l}\text { per } \\
\text { cent }\end{array}$ & $\begin{array}{l}\text { per } \\
\text { cent }\end{array}$ & $\begin{array}{l}\text { per } \\
\text { cent }\end{array}$ & per cent \\
\hline L02 & 13.75 & 0.71 & 36.0 & 2.7 & 65.6 & 21.3 & 14.7 & 0.0 & 42.6 & 0.0 & 0.0 & 10.7 & 2.3 & 0.0 & 8.4 \\
\hline L05a & 7.33 & 1.56 & 21.5 & 2.7 & 72.6 & 80.4 & 5.4 & 0.0 & 3.6 & 0.0 & 0.0 & 0.0 & 7.8 & 0.0 & 2.9 \\
\hline L05b & 7.33 & 1.56 & 6.5 & 2.7 & 285.1 & 80.4 & 5.4 & 0.0 & 3.6 & 0.0 & 0.0 & 0.0 & 7.8 & 0.0 & 2.9 \\
\hline L06 & 30.88 & 11.58 & 26.4 & 2.6 & 225.5 & 38.4 & 15.5 & 0.0 & 21.9 & 0.0 & 0.0 & 6.9 & 0.0 & 0.0 & 13.1 \\
\hline L09 & 36.42 & 12.07 & 27.5 & 2.8 & 264.8 & 49.3 & 28.3 & 0.0 & 11.3 & 0.0 & 0.0 & 4.3 & 0.0 & 0.0 & 6.9 \\
\hline L10 & 23.16 & 0.96 & 30.2 & 2.9 & 153.6 & 68.6 & 20.9 & 0.0 & 1.0 & 0.0 & 0.0 & 3.5 & 3.8 & 0.0 & 2.2 \\
\hline L11 & 21.95 & 0.76 & 22.1 & 2.9 & 225.0 & 51.0 & 21.8 & 0.0 & 6.3 & 0.0 & 0.0 & 0.4 & 4.8 & 5.4 & 10.2 \\
\hline L12a & 5.07 & 2.31 & 3.9 & 3.0 & 376.0 & 90.1 & 4.2 & 0.0 & 0.0 & 0.0 & 0.0 & 0.0 & 2.8 & 0.8 & 2.0 \\
\hline L12b & 5.07 & 2.31 & 4.7 & 3.1 & 317.6 & 90.1 & 4.2 & 0.0 & 0.0 & 0.0 & 0.0 & 0.0 & 2.8 & 0.8 & 2.0 \\
\hline L14 & 34.25 & 3.78 & 39.5 & 2.7 & 140.5 & 23.6 & 37.5 & 0.0 & 28.3 & 0.0 & 0.0 & 4.4 & 0.0 & 0.0 & 6.3 \\
\hline L15 & 17.17 & 1.54 & 10.5 & 2.9 & 428.7 & 79.7 & 15.5 & 0.0 & 0.0 & 0.0 & 0.0 & 0.1 & 2.7 & 0.0 & 2.0 \\
\hline L16 & 19.88 & 1.25 & 9.8 & 2.8 & 518.2 & 76.4 & 8.4 & 0.0 & 2.5 & 0.0 & 0.0 & 0.0 & 3.5 & 2.4 & 6.9 \\
\hline L19 & 20.65 & 6.19 & 21.6 & 2.9 & 213.9 & 34.3 & 13.5 & 0.0 & 4.3 & 0.0 & 0.0 & 12.9 & 0.0 & 8.1 & 27.0 \\
\hline L21 & 25.09 & 6.17 & 14.9 & 2.9 & 411.6 & 76.2 & 13.3 & 0.0 & 0.0 & 0.0 & 0.0 & 0.9 & 3.5 & 2.2 & 3.8 \\
\hline L22 & 23.16 & 3.44 & 13.9 & 2.8 & 401.9 & 46.7 & 14.5 & 0.0 & 5.8 & 0.0 & 0.0 & 5.7 & 0.0 & 5.7 & 21.6 \\
\hline L24a & 28.46 & 10.13 & 22.2 & 2.8 & 276.3 & 36.4 & 26.6 & 0.0 & 5.3 & 0.0 & 0.0 & 13.3 & 0.0 & 7.4 & 11.0 \\
\hline L24b & 28.46 & 10.13 & 17.8 & 2.8 & 367.7 & 36.4 & 26.6 & 0.0 & 5.3 & 0.0 & 0.0 & 13.3 & 0.0 & 7.4 & 11.0 \\
\hline L25 & 12.78 & 0.24 & 34.4 & 2.8 & 68.4 & 11.3 & 17.2 & 27.5 & 2.3 & 25.9 & 0.0 & 9.7 & 0.0 & 4.0 & 2.0 \\
\hline L26 & 14.23 & 3.11 & 9.9 & 2.9 & 375.8 & 73.4 & 19.0 & 0.0 & 0.0 & 0.0 & 0.0 & 0.6 & 3.7 & 0.0 & 3.4 \\
\hline L28 & 33.77 & 4.82 & 13.6 & 2.8 & 605.8 & 65.9 & 20.0 & 0.0 & 1.4 & 0.0 & 0.0 & 1.3 & 0.0 & 7.7 & 3.7 \\
\hline L29 & 15.58 & 6.33 & 17.7 & 2.8 & 205.1 & 73.4 & 12.3 & 0.0 & 0.0 & 0.0 & 0.0 & 0.1 & 0.0 & 3.2 & 11.0 \\
\hline L30 & 11.34 & 0.24 & 5.0 & 2.8 & 616.3 & 84.0 & 6.3 & 0.0 & 0.0 & 0.0 & 0.0 & 0.0 & 2.5 & 5.1 & 2.2 \\
\hline L31 & 32.56 & 1.69 & 23.6 & 2.8 & 291.5 & 53.8 & 19.8 & 3.1 & 0.0 & 0.0 & 0.0 & 2.4 & 0.0 & 4.8 & 16.1 \\
\hline L116 & 9.02 & 1.14 & 11.3 & 2.9 & 209.0 & 84.4 & 3.0 & 0.0 & 5.2 & 0.0 & 0.0 & 0.0 & 1.3 & 0.0 & 5.1 \\
\hline L117 & 6.86 & 0.10 & 5.1 & 2.9 & 371.1 & 86.8 & 9.4 & 0.0 & 0.5 & 0.0 & 0.0 & 0.1 & 0.0 & 0.0 & 3.3 \\
\hline L118 & 6.88 & 0.49 & 4.9 & 2.9 & 387.9 & 85.4 & 11.6 & 0.0 & 0.6 & 0.0 & 0.0 & 0.0 & 0.0 & 0.0 & 2.4 \\
\hline L119 & 54.03 & 0.96 & 26.9 & 2.6 & 380.0 & 13.5 & 44.5 & 0.0 & 34.2 & 0.0 & 0.0 & 0.6 & 0.0 & 0.0 & 7.2 \\
\hline L120 & 14.53 & 0.58 & 39.0 & 2.8 & 62.4 & 8.0 & 21.5 & 13.7 & 28.6 & 0.0 & 0.0 & 0.4 & 2.6 & 0.0 & 25.3 \\
\hline L121 & 31.36 & 0.48 & 40.1 & 2.7 & 126.7 & 12.2 & 28.3 & 16.5 & 0.0 & 18.2 & 1.3 & 0.4 & 0.0 & 0.0 & 23.3 \\
\hline L122 & 24.90 & 1.24 & 38.7 & 2.8 & 109.8 & 8.6 & 37.2 & 15.4 & 7.4 & 0.0 & 0.0 & 0.0 & 2.7 & 0.0 & 28.8 \\
\hline L123 & 35.22 & 2.45 & 36.5 & 2.7 & 167.7 & 0.0 & 51.4 & 8.0 & 0.0 & 0.0 & 0.0 & 0.0 & 0.0 & 3.2 & 37.4 \\
\hline L35 & 20.99 & 0.24 & 12.1 & 2.6 & 398.7 & 52.0 & 47.4 & 0.0 & 0.0 & 0.0 & 0.0 & 0.0 & 0.6 & 0.0 & 0.0 \\
\hline L36 & 3.14 & 0.72 & 13.9 & 2.8 & 54.3 & 72.5 & 3.6 & 8.5 & 10.3 & 0.6 & 0.0 & 0.0 & 4.4 & 0.0 & 0.0 \\
\hline L37 & 5.45 & 0.14 & 24.8 & 2.8 & 45.5 & 34.3 & 11.1 & 10.3 & 4.5 & 0.0 & 0.0 & 0.4 & 0.0 & 0.0 & 39.5 \\
\hline L40 & 10.47 & 0.34 & 23.4 & 2.8 & 95.7 & 27.9 & 18.4 & 11.5 & 4.3 & 0.0 & 0.0 & 0.0 & 0.0 & 0.0 & 37.9 \\
\hline L41 & 4.10 & 0.24 & 11.3 & 2.8 & 91.0 & 4.3 & 6.1 & 4.9 & 0.0 & 0.0 & 0.0 & 9.4 & 0.0 & 0.0 & 75.2 \\
\hline L42 & 6.75 & 0.48 & 30.6 & 2.7 & 41.6 & 0.0 & 17.9 & 3.7 & 0.0 & 42.8 & 6.0 & 0.4 & 0.0 & 4.1 & 25.1 \\
\hline L43 & 0.63 & 0.14 & 18.3 & 3.0 & 8.5 & 73.3 & 0.0 & 12.2 & 0.0 & 0.0 & 0.0 & 0.7 & 0.0 & 7.2 & 6.7 \\
\hline L44 & 0.92 & 0.05 & 21.4 & 3.0 & 10.0 & 59.6 & 0.0 & 10.1 & 0.0 & 6.9 & 1.0 & 4.4 & 0.0 & 5.9 & 12.1 \\
\hline L45 & 0.68 & 0.10 & 27.1 & 2.9 & 5.3 & 75.0 & 0.0 & 11.6 & 0.0 & 1.8 & 0.0 & 0.3 & 0.0 & 4.4 & 6.9 \\
\hline L46a & 0.43 & 0.34 & 24.4 & 3.0 & 4.0 & 70.5 & 0.0 & 9.1 & 5.6 & 0.0 & 0.0 & 0.0 & 4.7 & 5.7 & 4.5 \\
\hline L46b & 0.43 & 0.34 & 23.4 & 3.0 & 4.3 & 70.5 & 0.0 & 9.1 & 5.6 & 0.0 & 0.0 & 0.0 & 4.7 & 5.7 & 4.5 \\
\hline L47 & 0.34 & 0.05 & 24.0 & 3.0 & 3.2 & 71.2 & 0.0 & 10.5 & 0.0 & 0.0 & 0.0 & 0.0 & 6.3 & 5.5 & 6.5 \\
\hline L48 & 0.34 & 0.34 & 20.5 & 3.0 & 3.9 & 76.8 & 0.0 & 5.5 & 0.9 & 8.1 & 0.0 & 0.0 & 3.2 & 0.0 & 5.7 \\
\hline L49 & 0.19 & 0.19 & 10.3 & 3.0 & 5.1 & 79.3 & 0.0 & 10.9 & 0.0 & 0.0 & 0.0 & 0.0 & 0.0 & 2.9 & 6.9 \\
\hline L50 & 0.24 & 0.24 & 23.2 & 3.0 & 2.4 & 65.4 & 0.0 & 11.9 & 0.0 & 8.1 & 0.0 & 0.0 & 1.9 & 4.0 & 8.7 \\
\hline L51 & 0.77 & 0.10 & 28.1 & 3.0 & 5.8 & 63.8 & 0.0 & 23.4 & 0.0 & 0.0 & 0.6 & 0.0 & 0.0 & 0.0 & 12.2 \\
\hline L52 & 5.11 & 0.29 & 14.4 & 2.8 & 84.3 & 40.9 & 7.9 & 29.1 & 0.0 & 2.1 & 0.0 & 0.2 & 0.0 & 3.7 & 15.9 \\
\hline L54 & 1.64 & 1.25 & 15.9 & 2.8 & 24.3 & 47.2 & 11.2 & 14.6 & 6.4 & 5.0 & 10.5 & 0.0 & 0.0 & 3.1 & 2.1 \\
\hline L55 & 2.12 & 0.19 & 16.0 & 2.8 & 30.8 & 79.1 & 9.1 & 8.5 & 0.0 & 0.4 & 2.0 & 0.0 & 0.0 & 0.0 & 0.8 \\
\hline L56 & 2.17 & 0.24 & 30.3 & 2.7 & 13.6 & 23.5 & 4.1 & 13.5 & 0.0 & 24.4 & 31.6 & 0.0 & 0.0 & 1.4 & 1.6 \\
\hline L57 & 1.16 & 0.48 & 32.0 & 2.9 & 7.1 & 33.4 & 0.0 & 17.6 & 0.0 & 0.0 & 8.7 & 0.0 & 2.4 & 3.9 & 33.9 \\
\hline L58 & 3.38 & 0.48 & 12.7 & 3.0 & 68.8 & 58.1 & 6.7 & 21.6 & 0.0 & 0.0 & 3.1 & 1.3 & 0.0 & 6.0 & 3.1 \\
\hline L59 & 3.81 & 0.24 & 21.9 & 2.8 & 38.5 & 43.9 & 12.5 & 21.3 & 0.0 & 0.0 & 12.2 & 0.0 & 0.0 & 7.3 & 2.8 \\
\hline L60 & 7.24 & 0.48 & 18.5 & 2.9 & 90.8 & 58.6 & 10.4 & 20.7 & 0.0 & 0.0 & 0.0 & 0.0 & 0.0 & 7.7 & 2.6 \\
\hline L61 & 2.75 & 0.63 & 34.7 & 2.9 & 14.9 & 33.7 & 0.0 & 29.9 & 0.0 & 0.0 & 9.3 & 0.0 & 0.0 & 5.7 & 18.2 \\
\hline L69 & 1.78 & 0.34 & 34.7 & 2.9 & 9.8 & 36.2 & 0.0 & 10.9 & 0.0 & 0.0 & 36.7 & 0.1 & 0.0 & 8.0 & 8.1 \\
\hline L71 & 5.35 & 0.24 & 37.1 & 2.9 & 26.4 & 36.9 & 0.0 & 28.2 & 1.2 & 0.0 & 23.2 & 0.0 & 0.0 & 6.9 & 3.7 \\
\hline L62 & 0.77 & 0.10 & 18.5 & 2.9 & 9.9 & 61.7 & 0.0 & 14.9 & 0.0 & 0.0 & 6.0 & 0.3 & 0.0 & 0.0 & 17.5 \\
\hline L73 & 1.54 & 0.39 & 31.0 & 3.0 & 10.3 & 55.9 & 0.0 & 23.9 & 0.0 & 0.0 & 8.6 & 0.0 & 3.2 & 8.3 & 0.0 \\
\hline
\end{tabular}


Table B1. Continued

\begin{tabular}{|c|c|c|c|c|c|c|c|c|c|c|c|c|c|c|c|}
\hline ID & CEC & $\begin{array}{l}\text { Unc } \\
\text { CEC }\end{array}$ & Poro & $\begin{array}{c}\text { Grain } \\
\text { density }\end{array}$ & $Q \mathrm{v}$ & $\begin{array}{c}\text { Plg \& O1 } \\
\text { \& Pyx }\end{array}$ & $\begin{array}{l}\text { Smec or } \\
\text { MLC }\end{array}$ & Chl & Zeol & Wai & $\begin{array}{c}\text { Amp \& } \\
\text { Ep \& Pre }\end{array}$ & Pyr & $\mathrm{Fe}-\mathrm{ox}$ & Tit & $\begin{array}{c}\text { Qtz \& } \\
\text { Clc }\end{array}$ \\
\hline L66 & 1.16 & 0.19 & 22.3 & 2.9 & 11.8 & 67.9 & 0.0 & 14.6 & 0.0 & 0.0 & 4.1 & 0.3 & 0.0 & 5.7 & 7.1 \\
\hline $\mathrm{L} 67 \mathrm{a}$ & 0.43 & 0.39 & 25.2 & 2.8 & 3.7 & 36.4 & 0.0 & 19.9 & 0.0 & 0.0 & 6.4 & 0.5 & 0.0 & 0.0 & 36.8 \\
\hline L67b & 0.43 & 0.39 & 27.4 & 2.8 & 3.2 & 36.4 & 0.0 & 19.9 & 0.0 & 0.0 & 6.4 & 0.5 & 0.0 & 0.0 & 36.8 \\
\hline L75 & 0.63 & 0.34 & 24.7 & 2.9 & 5.6 & 62.4 & 0.0 & 7.1 & 0.0 & 0.0 & 16.2 & 0.7 & 2.0 & 6.1 & 5.5 \\
\hline L76 & 1.16 & 0.10 & 9.9 & 3.0 & 31.6 & 65.0 & 0.0 & 21.1 & 0.0 & 0.0 & 11.1 & 0.0 & 0.1 & 0.0 & 2.7 \\
\hline L106 & 1.00 & 0.22 & 1.9 & 3.0 & 157.1 & 95.5 & 1.3 & 0.0 & 0.0 & 0.0 & 0.0 & 0.0 & 3.2 & 0.0 & 0.0 \\
\hline L107 & 20.33 & 0.27 & 36.6 & 2.8 & 99.2 & 13.5 & 17.8 & 42.9 & 0.0 & 0.0 & 0.0 & 0.0 & 0.4 & 0.0 & 25.4 \\
\hline L108 & 9.95 & 0.91 & 5.9 & 2.9 & 452.8 & 71.5 & 19.7 & 3.9 & 0.0 & 0.2 & 0.0 & 0.0 & 0.0 & 0.0 & 4.8 \\
\hline L109 & 7.20 & 0.87 & 4.3 & 2.9 & 470.2 & 76.8 & 14.3 & 3.4 & 0.0 & 0.1 & 0.0 & 0.0 & 0.0 & 0.0 & 5.4 \\
\hline L110 & 9.12 & 0.51 & 15.4 & 2.8 & 140.3 & 10.6 & 9.9 & 34.4 & 0.0 & 0.5 & 0.0 & 0.3 & 0.0 & 0.0 & 44.3 \\
\hline L111 & 6.82 & 0.86 & 5.1 & 2.7 & 349.3 & 47.2 & 15.0 & 20.5 & 0.0 & 0.0 & 0.0 & 0.5 & 0.0 & 0.0 & 16.9 \\
\hline L112 & 6.14 & 0.65 & 4.2 & 2.8 & 400.8 & 45.1 & 12.1 & 17.5 & 0.0 & 0.1 & 0.0 & 0.1 & 0.0 & 0.0 & 25.1 \\
\hline L113 & 3.46 & 0.25 & 9.9 & 2.9 & 92.5 & 50.9 & 8.8 & 24.1 & 0.0 & 0.3 & 0.0 & 0.1 & 0.0 & 0.0 & 15.9 \\
\hline L114 & 2.54 & 0.38 & 7.3 & 2.9 & 91.6 & 68.6 & 5.9 & 17.0 & 0.0 & 0.0 & 0.0 & 0.0 & 0.0 & 0.0 & 8.6 \\
\hline L115 & 5.98 & 1.50 & 14.8 & 2.8 & 95.2 & 37.0 & 11.0 & 28.9 & 0.0 & 0.0 & 0.0 & 0.0 & 0.0 & 0.0 & 23.1 \\
\hline L81 & 20.26 & 0.96 & 8.0 & 2.9 & 676.7 & 75.0 & 15.7 & 0.0 & 0.0 & 0.0 & 2.3 & 0.1 & 2.7 & 0.0 & 4.2 \\
\hline L82 & 5.55 & 0.72 & 34.1 & 2.9 & 31.2 & 65.6 & 7.1 & 17.8 & 0.0 & 0.0 & 0.0 & 2.3 & 0.0 & 3.7 & 3.5 \\
\hline L85 & 3.86 & 0.29 & 2.8 & 2.9 & 386.2 & 79.6 & 9.6 & 3.6 & 1.6 & 0.0 & 0.0 & 0.0 & 0.0 & 5.6 & 0.0 \\
\hline L87 & 5.40 & 0.39 & 23.7 & 2.9 & 50.7 & 70.1 & 7.3 & 7.7 & 0.0 & 0.0 & 0.0 & 0.0 & 0.0 & 5.4 & 9.4 \\
\hline L91 & 8.10 & 0.19 & 11.1 & 2.9 & 185.6 & 67.7 & 17.2 & 3.4 & 0.0 & 0.0 & 0.0 & 0.0 & 0.0 & 0.0 & 11.7 \\
\hline L93 & 1.78 & 0.53 & 24.0 & 2.8 & 16.1 & 59.3 & 0.0 & 6.5 & 0.0 & 0.0 & 3.9 & 0.6 & 1.9 & 4.3 & 23.6 \\
\hline L96 & 31.36 & 6.27 & 27.9 & 2.7 & 217.9 & 32.2 & 28.1 & 3.8 & 3.0 & 12.7 & 6.6 & 1.1 & 0.0 & 8.3 & 4.3 \\
\hline L99 & 32.80 & 0.19 & 30.5 & 2.7 & 202.7 & 18.6 & 27.1 & 12.3 & 27.4 & 0.0 & 4.5 & 0.0 & 0.0 & 8.8 & 0.0 \\
\hline L100 & 0.96 & 0.19 & 18.5 & 2.8 & 11.9 & 77.4 & 2.4 & 0.0 & 0.0 & 1.2 & 5.0 & 0.7 & 1.1 & 5.0 & 6.7 \\
\hline L102 & 9.84 & 0.19 & 25.3 & 2.7 & 77.8 & 34.6 & 18.3 & 21.6 & 0.0 & 8.8 & 5.0 & 0.0 & 0.0 & 3.8 & 5.8 \\
\hline L103 & 5.93 & 0.14 & 17.0 & 3.0 & 85.9 & 64.6 & 5.2 & 12.0 & 0.0 & 0.0 & 0.0 & 0.0 & 2.2 & 6.0 & 3.5 \\
\hline L104 & 21.78 & 0.67 & 12.4 & 3.0 & 455.3 & 75.2 & 17.9 & 0.0 & 1.3 & 0.0 & 0.0 & 0.0 & 0.0 & 0.0 & 5.7 \\
\hline L105 & 24.85 & 0.33 & 21.1 & 2.7 & 255.3 & 17.7 & 22.8 & 10.8 & 0.0 & 31.2 & 7.9 & 0.0 & 2.7 & 7.0 & 0.0 \\
\hline
\end{tabular}


Table C1. Parameters from four fits: Linear (Lin), Exponential (Exp), Power (Pow) and Equivalent Circuit (EC).

\begin{tabular}{|c|c|c|c|c|c|c|c|c|c|c|c|c|}
\hline \multirow[b]{2}{*}{ Parameter } & \multicolumn{4}{|c|}{ Formation factor } & \multicolumn{4}{|c|}{ EDL conduction } & \multicolumn{4}{|c|}{ Other parameters } \\
\hline & $1 / a 0$ & $1 / a 1$ & $1 / a$ & $1 / a 2$ & $c 0$ & $c 1$ & $c$ & $b 2$ & $b$ & $\gamma$ & $c 2$ & $d 2$ \\
\hline Fit type & Lin & Exp & Pow & $\mathrm{EC}$ & Lin & Exp & Pow & $\mathrm{EC}$ & Pow & Exp & $\mathrm{EC}$ & $\mathrm{EC}$ \\
\hline L5a & 114 & 136 & 56 & 165 & $9.6 \mathrm{E}-03$ & 2.1E-02 & $3.2 \mathrm{E}-03$ & 4.2E-03 & 0.7 & 1.4 & $1.5 \mathrm{E}-02$ & $3.6 \mathrm{E}-02$ \\
\hline L5b & 466 & 503 & 262 & 548 & $3.2 \mathrm{E}-03$ & 4.3E-03 & $2.0 \mathrm{E}-03$ & $2.0 \mathrm{E}-03$ & 0.8 & 0.1 & $5.1 \mathrm{E}-03$ & $4.0 \mathrm{E}-03$ \\
\hline L6 & 70 & 83 & 36 & 84 & $2.5 \mathrm{E}-02$ & 4.3E-02 & $1.6 \mathrm{E}-02$ & $1.5 \mathrm{E}-02$ & 0.7 & 0.8 & $4.9 \mathrm{E}-02$ & $3.2 \mathrm{E}-02$ \\
\hline L11 & 146 & 167 & 59 & 207 & $2.0 \mathrm{E}-02$ & 2.7E-02 & $1.3 \mathrm{E}-02$ & $1.4 \mathrm{E}-02$ & 0.6 & 0.1 & 2.3E- 02 & $2.6 \mathrm{E}-02$ \\
\hline $\mathrm{L} 12 \mathrm{a}$ & 838 & 1016 & 385 & 1009 & $2.3 \mathrm{E}-03$ & $3.8 \mathrm{E}-03$ & $1.3 \mathrm{E}-03$ & $7.4 \mathrm{E}-04$ & 0.7 & 0.5 & $1.8 \mathrm{E}-02$ & $3.1 \mathrm{E}-03$ \\
\hline L12b & 491 & 636 & 193 & 719 & $3.2 \mathrm{E}-03$ & $6.7 \mathrm{E}-03$ & $9.7 \mathrm{E}-04$ & $1.3 \mathrm{E}-03$ & 0.6 & 1.2 & $6.3 \mathrm{E}-03$ & 7.9E-03 \\
\hline L14 & 23 & 28 & 11 & 29 & $5.8 \mathrm{E}-02$ & $1.2 \mathrm{E}-01$ & $3.4 \mathrm{E}-02$ & $2.8 \mathrm{E}-02$ & 0.7 & 1.3 & $3.5 \mathrm{E}-01$ & $1.1 \mathrm{E}-01$ \\
\hline L15 & 216 & 239 & 104 & 270 & $1.1 \mathrm{E}-02$ & $1.4 \mathrm{E}-02$ & 7.2E-03 & 7.3E-03 & 0.7 & 0.1 & $1.4 \mathrm{E}-02$ & $1.2 \mathrm{E}-02$ \\
\hline L16 & 250 & 268 & 132 & 287 & $1.2 \mathrm{E}-02$ & $1.4 \mathrm{E}-02$ & $9.9 \mathrm{E}-03$ & $9.3 \mathrm{E}-03$ & 0.7 & 0.0 & $1.9 \mathrm{E}-02$ & 7.4E-03 \\
\hline L24b & 118 & 141 & 35 & 167 & 4.6E- 02 & $5.6 \mathrm{E}-02$ & $3.2 \mathrm{E}-02$ & $3.3 \mathrm{E}-02$ & 0.5 & 0.1 & 7.7E-02 & $3.4 \mathrm{E}-02$ \\
\hline L25 & 34 & 47 & 11 & 51 & $7.8 \mathrm{E}-02$ & $1.5 \mathrm{E}-01$ & $3.8 \mathrm{E}-02$ & $4.5 \mathrm{E}-02$ & 0.6 & 1.1 & $1.2 \mathrm{E}-01$ & $1.3 \mathrm{E}-01$ \\
\hline L26 & 177 & 190 & 114 & 196 & $9.5 \mathrm{E}-03$ & $1.2 \mathrm{E}-02$ & 7.3E-03 & $6.0 \mathrm{E}-03$ & 0.8 & 0.1 & $3.1 \mathrm{E}-02$ & $7.9 \mathrm{E}-03$ \\
\hline L28 & 558 & 637 & 210 & 703 & $8.0 \mathrm{E}-03$ & $9.5 \mathrm{E}-03$ & $5.8 \mathrm{E}-03$ & $5.4 \mathrm{E}-03$ & 0.6 & 0.0 & 2.4E- 02 & $5.4 \mathrm{E}-03$ \\
\hline L29 & 116 & 134 & 62 & 138 & $1.3 \mathrm{E}-02$ & 2.2E-02 & $7.5 \mathrm{E}-03$ & $6.9 \mathrm{E}-03$ & 0.7 & 0.7 & 3.0E-02 & $1.8 \mathrm{E}-02$ \\
\hline L30 & 891 & 1407 & 128 & 1397 & $5.0 \mathrm{E}-03$ & $8.2 \mathrm{E}-03$ & $6.7 \mathrm{E}-07$ & $2.8 \mathrm{E}-03$ & 0.3 & 0.5 & $1.2 \mathrm{E}-02$ & $5.9 \mathrm{E}-03$ \\
\hline L31 & 65 & 91 & 23 & 94 & $4.2 \mathrm{E}-02$ & 7.6E-02 & 2.3E-02 & $2.5 \mathrm{E}-02$ & 0.6 & 1.0 & 7.0E-02 & $6.0 \mathrm{E}-02$ \\
\hline L116 & 312 & 326 & 187 & 371 & 4.3E-03 & $5.5 \mathrm{E}-03$ & $2.9 \mathrm{E}-03$ & $3.0 \mathrm{E}-03$ & 0.8 & 0.1 & $3.8 \mathrm{E}-03$ & 7.4E-03 \\
\hline L117 & 966 & 6946 & 136 & 1999 & 4.7E- 03 & $1.3 \mathrm{E}-02$ & $1.5 \mathrm{E}-08$ & $1.8 \mathrm{E}-03$ & 0.3 & 2.1 & $1.0 \mathrm{E}-02$ & $9.8 \mathrm{E}-03$ \\
\hline L118 & 660 & 693 & 319 & 849 & 3.3E-03 & 4.0E-03 & $2.2 \mathrm{E}-03$ & $2.4 \mathrm{E}-03$ & 0.7 & 0.1 & $2.7 \mathrm{E}-03$ & $4.9 \mathrm{E}-03$ \\
\hline L119 & 75 & 79 & 32 & 106 & $5.4 \mathrm{E}-02$ & $6.0 \mathrm{E}-02$ & 4.1E-02 & 4.3E-02 & 0.7 & 0.0 & 3.0E-02 & $5.9 \mathrm{E}-02$ \\
\hline L120 & 33 & 38 & 21 & 91 & $2.7 \mathrm{E}-02$ & $6.2 \mathrm{E}-02$ & $1.4 \mathrm{E}-02$ & $1.8 \mathrm{E}-02$ & 0.8 & 2.2 & $3.1 \mathrm{E}-02$ & $5.8 \mathrm{E}-01$ \\
\hline L121 & 30 & 38 & 16 & 41 & $5.8 \mathrm{E}-02$ & $1.3 \mathrm{E}-01$ & $3.2 \mathrm{E}-02$ & $3.7 \mathrm{E}-02$ & 0.7 & 2.3 & 4.5E-02 & $1.4 \mathrm{E}-01$ \\
\hline L43 & 73 & 77 & 56 & 79 & $4.0 \mathrm{E}-03$ & $8.8 \mathrm{E}-03$ & $8.9 \mathrm{E}-04$ & 5.1E-04 & 0.9 & 1.0 & $1.3 \mathrm{E}-02$ & $1.4 \mathrm{E}-02$ \\
\hline L44 & 61 & 64 & 45 & 66 & $5.7 \mathrm{E}-03$ & $1.2 \mathrm{E}-02$ & $1.8 \mathrm{E}-03$ & $1.5 \mathrm{E}-03$ & 0.9 & 1.1 & $1.5 \mathrm{E}-02$ & $1.8 \mathrm{E}-02$ \\
\hline L45 & 29 & 31 & 21 & 70 & $1.1 \mathrm{E}-02$ & 2.7E-02 & $1.5 \mathrm{E}-03$ & $4.4 \mathrm{E}-03$ & 0.9 & 1.3 & $2.9 \mathrm{E}-02$ & $6.7 \mathrm{E}-01$ \\
\hline L46a & 32 & 34 & 24 & 80 & $8.1 \mathrm{E}-03$ & $2.0 \mathrm{E}-02$ & 4.3E-09 & $2.1 \mathrm{E}-03$ & 0.9 & 1.3 & 2.6E-02 & $7.2 \mathrm{E}-01$ \\
\hline L46b & 31 & 33 & 22 & 76 & $8.5 \mathrm{E}-03$ & 2.3E-02 & 1.7E-10 & $1.5 \mathrm{E}-03$ & 0.9 & 1.6 & $2.8 \mathrm{E}-02$ & $6.0 \mathrm{E}-01$ \\
\hline L47 & 34 & 36 & 25 & 39 & $9.2 \mathrm{E}-03$ & $2.1 \mathrm{E}-02$ & $1.8 \mathrm{E}-03$ & $1.9 \mathrm{E}-03$ & 0.9 & 1.1 & $2.1 \mathrm{E}-02$ & $4.2 \mathrm{E}-02$ \\
\hline L48 & 49 & 50 & 40 & 52 & 4.3E- 03 & $9.6 \mathrm{E}-03$ & $1.2 \mathrm{E}-03$ & $1.2 \mathrm{E}-03$ & 0.9 & 1.2 & $9.3 \mathrm{E}-03$ & $1.6 \mathrm{E}-02$ \\
\hline L49 & 164 & 176 & 107 & 198 & $2.5 \mathrm{E}-03$ & $5.8 \mathrm{E}-03$ & 2.3E-04 & 4.4E-04 & 0.8 & 1.1 & $6.0 \mathrm{E}-03$ & $1.4 \mathrm{E}-02$ \\
\hline L50 & 44 & 46 & 33 & 52 & $6.5 \mathrm{E}-03$ & $1.5 \mathrm{E}-02$ & $8.8 \mathrm{E}-04$ & $1.8 \mathrm{E}-03$ & 0.9 & 1.2 & $1.2 \mathrm{E}-02$ & $5.2 \mathrm{E}-02$ \\
\hline L51 & 38 & 39 & 33 & 39 & $5.9 \mathrm{E}-03$ & $1.1 \mathrm{E}-02$ & $3.1 \mathrm{E}-03$ & $6.8 \mathrm{E}-04$ & 0.9 & 0.5 & 4. $6 \mathrm{E}-02$ & $1.2 \mathrm{E}-02$ \\
\hline L52 & 130 & 140 & 86 & 141 & $7.0 \mathrm{E}-03$ & $1.1 \mathrm{E}-02$ & 4.3E-03 & $2.7 \mathrm{E}-03$ & 0.8 & 0.4 & 3.6E-02 & $9.7 \mathrm{E}-03$ \\
\hline L54 & 119 & 124 & 96 & 126 & $2.0 \mathrm{E}-03$ & 4.7E-03 & 5.7E-04 & $9.9 \mathrm{E}-04$ & 0.9 & 1.4 & 3.6E-03 & $6.0 \mathrm{E}-03$ \\
\hline L55 & 81 & 85 & 61 & 89 & $4.5 \mathrm{E}-03$ & $9.8 \mathrm{E}-03$ & $1.6 \mathrm{E}-03$ & $1.6 \mathrm{E}-03$ & 0.9 & 1.2 & $9.9 \mathrm{E}-03$ & $1.4 \mathrm{E}-02$ \\
\hline L56 & 30 & 32 & 22 & 80 & $1.2 \mathrm{E}-02$ & $2.7 \mathrm{E}-02$ & $2.7 \mathrm{E}-03$ & $5.4 \mathrm{E}-03$ & 0.9 & 1.4 & $2.9 \mathrm{E}-02$ & 8.0E-01 \\
\hline L57 & 21 & 24 & 12 & 164 & $2.4 \mathrm{E}-02$ & $6.7 \mathrm{E}-02$ & 4.3E-09 & $3.8 \mathrm{E}-03$ & 0.8 & 1.7 & $6.9 \mathrm{E}-02$ & $1.0 \mathrm{E}+00$ \\
\hline L58 & 328 & 347 & 226 & 355 & $2.0 \mathrm{E}-03$ & 3.3E-03 & $1.0 \mathrm{E}-03$ & $9.4 \mathrm{E}-04$ & 0.8 & 0.3 & 7.3E-03 & $3.0 \mathrm{E}-03$ \\
\hline L59 & 67 & 74 & 42 & 86 & $8.5 \mathrm{E}-03$ & $2.0 \mathrm{E}-02$ & $2.3 \mathrm{E}-03$ & $3.2 \mathrm{E}-03$ & 0.8 & 1.4 & $1.4 \mathrm{E}-02$ & 4.6E- 02 \\
\hline L60 & 156 & 170 & 100 & 178 & $4.3 \mathrm{E}-03$ & $8.2 \mathrm{E}-03$ & $1.8 \mathrm{E}-03$ & $1.7 \mathrm{E}-03$ & 0.8 & 0.9 & $9.9 \mathrm{E}-03$ & $1.0 \mathrm{E}-02$ \\
\hline L61 & 17 & 19 & 10 & 85 & $2.4 \mathrm{E}-02$ & $6.7 \mathrm{E}-02$ & 1.0E-09 & $2.7 \mathrm{E}-03$ & 0.8 & 1.6 & $7.5 \mathrm{E}-02$ & $1.3 \mathrm{E}+00$ \\
\hline L69 & 18 & 20 & 9 & 517 & $3.2 \mathrm{E}-02$ & $9.0 \mathrm{E}-02$ & $2.1 \mathrm{E}-10$ & $2.3 \mathrm{E}-03$ & 0.7 & 1.7 & $9.6 \mathrm{E}-02$ & $1.3 \mathrm{E}+00$ \\
\hline L71 & 25 & 28 & 16 & 83 & $1.8 \mathrm{E}-02$ & 4.6E- 02 & $1.2 \mathrm{E}-03$ & $6.1 \mathrm{E}-03$ & 0.8 & 1.6 & 4.4E-02 & 7.7E-01 \\
\hline L62 & 130 & 135 & 100 & 138 & $2.4 \mathrm{E}-03$ & 4.5E-03 & 7.6E-04 & $2.7 \mathrm{E}-04$ & 0.9 & 0.6 & $1.3 \mathrm{E}-02$ & $5.7 \mathrm{E}-03$ \\
\hline L73 & 45 & 47 & 34 & 53 & $6.1 \mathrm{E}-03$ & $1.5 \mathrm{E}-02$ & $8.8 \mathrm{E}-04$ & $1.5 \mathrm{E}-03$ & 0.9 & 1.4 & $1.2 \mathrm{E}-02$ & $4.9 \mathrm{E}-02$ \\
\hline L66 & 128 & 131 & 113 & 132 & $1.8 \mathrm{E}-03$ & 3.0E- 03 & $1.0 \mathrm{E}-03$ & $2.4 \mathrm{E}-04$ & 0.9 & 0.4 & $1.8 \mathrm{E}-02$ & $3.2 \mathrm{E}-03$ \\
\hline
\end{tabular}


Table C1. Continued

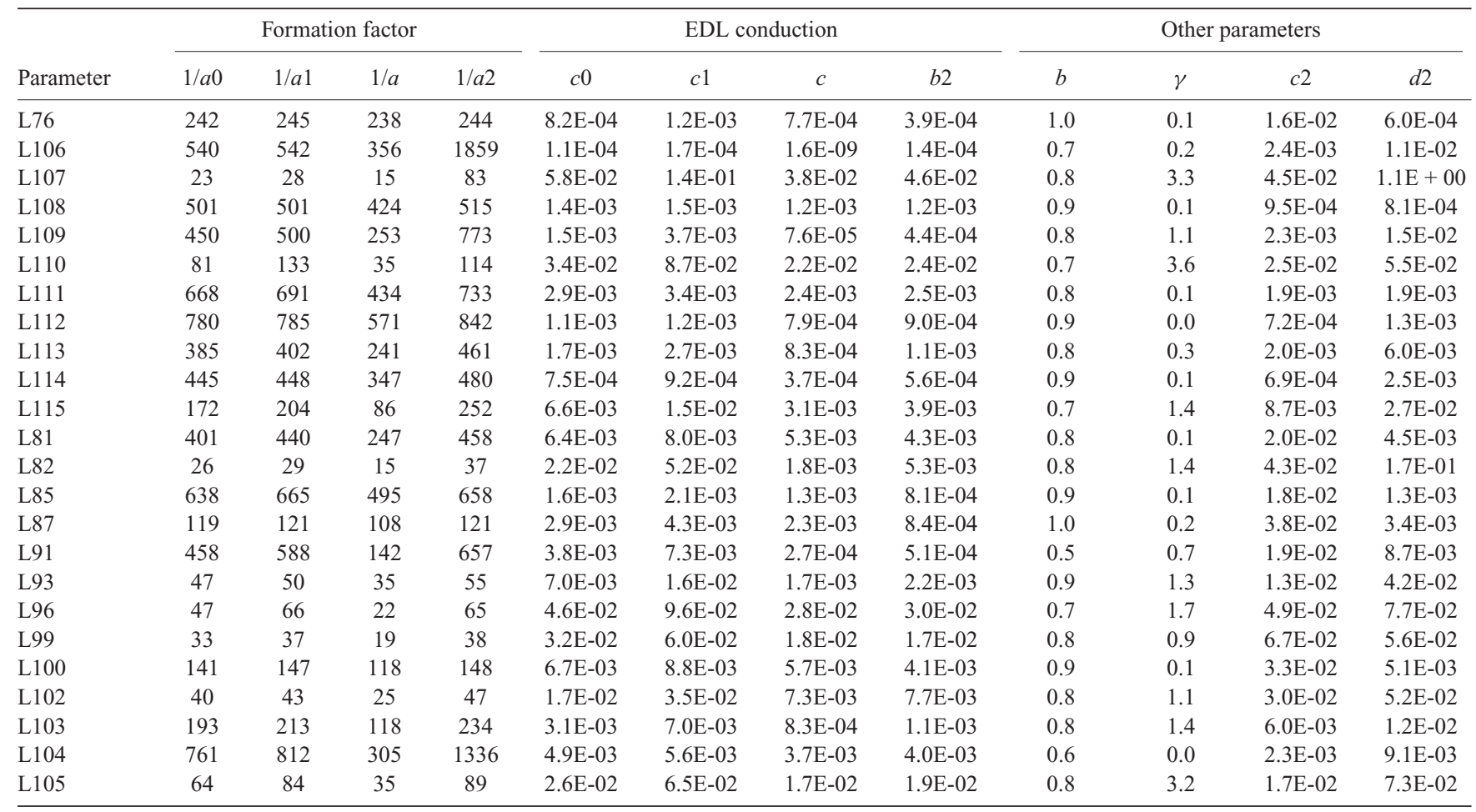

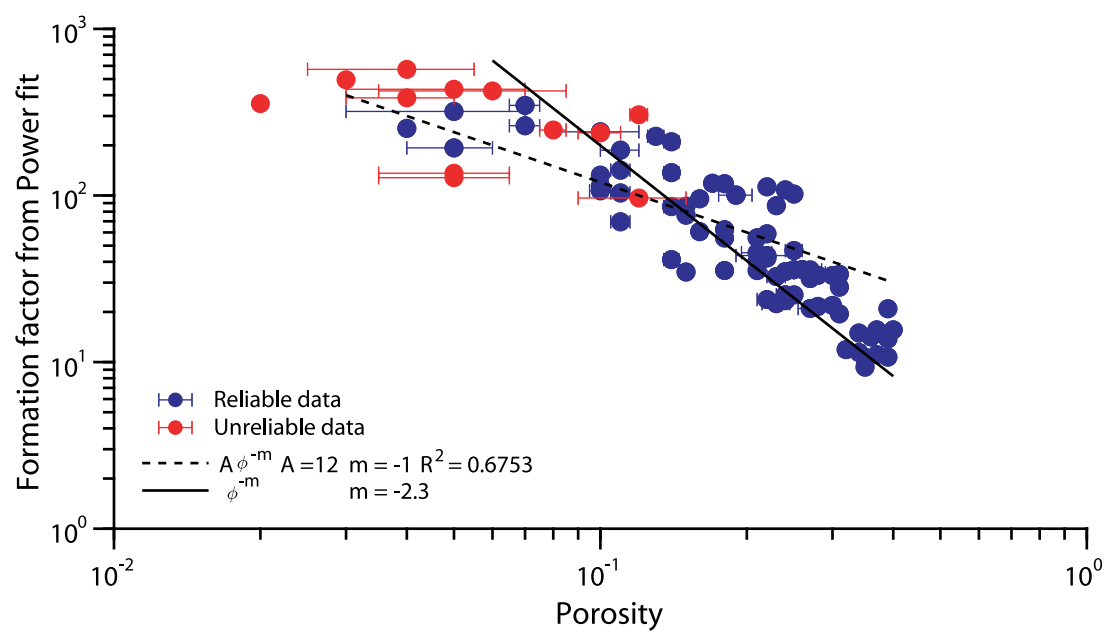

Figure C1. Formation factor (inverse of $a$ from Power fit) versus porosity. Two empirical equations describe the formation factor as a function of the porosity: $F=\phi^{-m}$ (Archie 1942) and $F=A \phi^{-m}$ (Winsauer et al. 1952). Twelve samples with unreliable electrical data are marked in red. These samples have porosity lower than 10 per cent. 


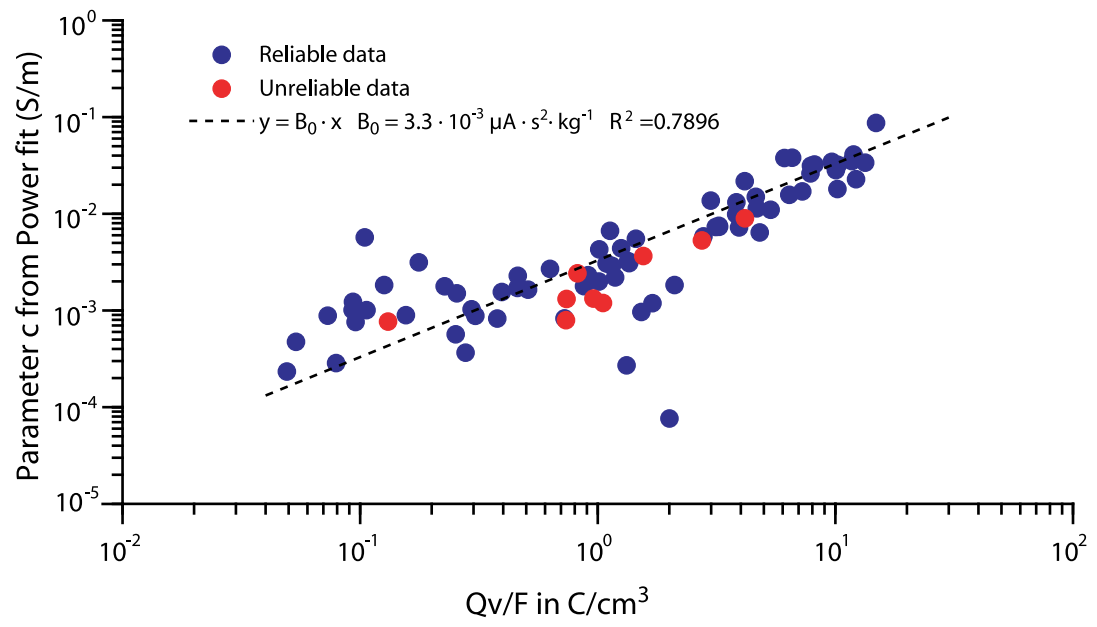

Figure C2. Parameter $c$ from Power fit versus $Q v / F$. The samples with unreliable electrical data are marked in red. For clarity purposes, five of them are absent of the figure because their parameter c takes value between $10^{-10}$ and $10^{-5} \mathrm{~S} \mathrm{~m}^{-1}$ although their $Q_{\mathrm{v}} / F$ is within the range shown in the figure. 